\title{
MENISCUS REPAIR AND REGENERATION: REVIEW ON CURRENT METHODS AND RESEARCH POTENTIAL
}

\author{
Celeste Scotti ${ }^{1}$, Michael T. Hirschmann ${ }^{2}$, Pierluigi Antinolfi ${ }^{3}$, Ivan Martin ${ }^{4 *}$ and Giuseppe M. Peretti ${ }^{1,5, *}$ \\ ${ }^{1}$ IRCCS Istituto Ortopedico Galeazzi, Milan, Italy \\ ${ }^{2}$ Department of Orthopaedic Surgery and Traumatology, Kantonsspital Bruderholz, Bruderholz, Switzerland \\ ${ }^{3}$ Ospedale S. Maria della Misericordia, University of Perugia, Perugia, Italy \\ ${ }^{4}$ Departments of Surgery and of Biomedicine, University Hospital Basel, Basel, Switzerland \\ ${ }^{5}$ Department of Biomedical Sciences for Health, University of Milan, Milan, Italy
}

\begin{abstract}
Meniscus regeneration is an unsolved clinical challenge. Despite the wide acceptance of the degenerative consequences of meniscectomy, no surgical procedure has succeeded to date in regenerating a functional and long-lasting meniscal fibrocartilage. Research proposed a number of experimental approaches encompassing all the typical strategies of regenerative medicine: cellfree scaffolds, gene therapy, intra-articular delivery of progenitor cells, biological glues for enhanced bonding of reparable tears, partial and total tissue engineered meniscus replacement. None of these approaches has been completely successful and can be considered suitable for all patients, as meniscal tears require specific and patientrelated treatments depending on the size and type of lesion. Recent advances in cell biology, biomaterial science and bioengineering (e.g., bioreactors) have now the potential to drive meniscus regeneration into a series of clinically relevant strategies. In this tutorial paper, the clinical need for meniscus regeneration strategies will be explained, and past and current experimental studies on meniscus regeneration will be reported.
\end{abstract}

Keywords: Meniscus; meniscal tear; tissue engineering; scaffold; bioreactor.

*Addresses for correspondence:

Prof. Ivan Martin

Institute for Surgical Research and Hospital Management Hebelstrasse 20, University Hospital Basel

4031 Basel, Switzerland

Telephone Number: +41612652379

FAX Number: +41612653990

E-mail: ivan.martin@usb.ch

Prof. Giuseppe M. Peretti

Department of Biomedical Sciences for Health, University of Milan

IRCCS Istituto Ortopedico Galeazzi

Via R. Galeazzi 4,

20161, Milan, Italy

Telephone Number: +390250319967

or +390266214735

Fax Number: +39026621 4736

E-mail: gperetti@iol.it

\section{Introduction}

Once described as "functionless remnants of leg muscle origin" (Bland Sutton, 1897), the menisci are now considered crucial structures for knee stability, shock absorption, and nutrient distribution to the articular cartilage (Ahmed and Burke, 1983; King, 1936; Krause et al., 1976; Levy et al., 1989; Seedhom and Hargreaves, 1979). However, their location and the extreme forces that the menisci can be subjected to make them frequently susceptible to injury, especially in contact-sport activities but also in sedentary young or elderly patients. Due in large part to the limited vascularity of the meniscus, which is restricted to the external third, this tissue has a poor healing potential (Arnoczky and Warren, 1982; Arnoczky and Warren, 1983). Although common in the past, total meniscectomy has been largely abandoned, for the direct relationship between meniscectomy and development of early osteoarthritis (Allen et al., 1984; Appel, 1970; Berjon et al., 1991; Ghosh et al., 1990; Hoch et al., 1983; Huckell, 1965; Jackson, 1968; Lufti, 1975; Northmore-Ball and Dandy, 1982; Voloshin and Wosk, 1983). Partial meniscectomy is still indicated if the lesion cannot be satisfactorily sutured (Sommerlath, 1991; Shelbourne and Carr, 2003). Regenerative medicine holds a great potential for restoring form and function of meniscal fibrocartilage. Specific considerations must be given to the type of cells necessary, the scaffold, and the physical forces within the microenvironment in which the meniscus is located. For these reasons, new strategies involving the use of bioreactors seem to be promising for the development of engineered meniscus tissue.

In this review, we will give an overview on the potential of research for meniscus regeneration, and provide a perspective, from the clinician's standpoint, for designing future regenerative strategies.

\section{Current perspectives on meniscus structure, lesions and treatment}

\section{Anatomy, composition and function}

The menisci are two semilunar or C-shaped fibrocartilage structures located medially and laterally between the femoral condyles and tibial plateau (King, 1936). They are crucial structures for knee joint homeostasis. Their function is to deepen the articular surfaces of the tibial plateau to better accommodate the condyles of the femur, providing knee stability, shock absorption, lubrication, proprioception and load distribution during motion. In 


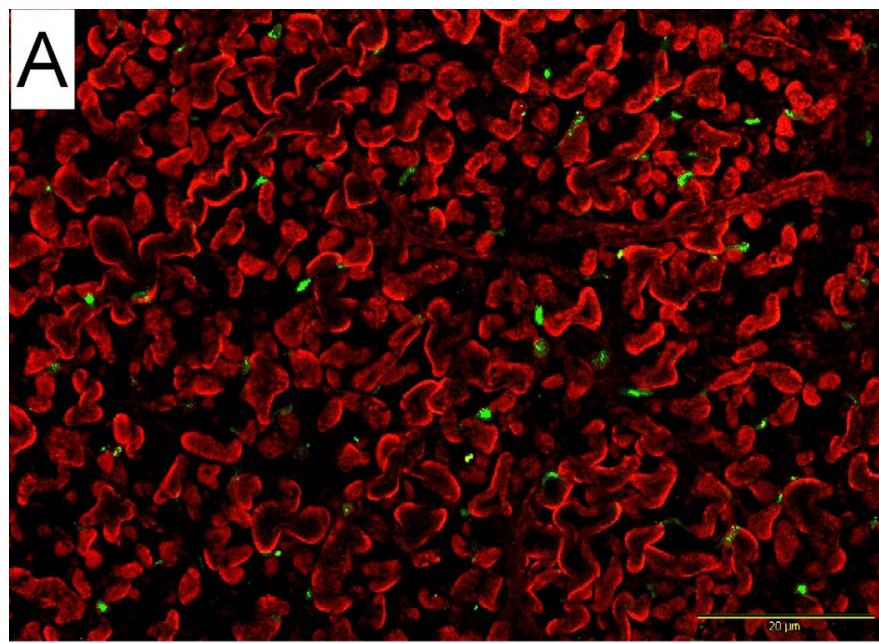

inner

Fig. 1. Anterior horn, young pig, double immunofluorescence of proliferating cell nuclear antigen (PCNA) and collagen type I staining: in the inner (A), middle (B) and outer (C) zone. A strong immunopositivity of collagen type I fibres (red colour) is evident with no differences in the three zones, while the proliferating cells (PCNA, green colour) revealed a higher degree in the outer zone (C), followed by the middle (B) and then by the inner one (A). Scale bar $20 \mu \mathrm{m}$.

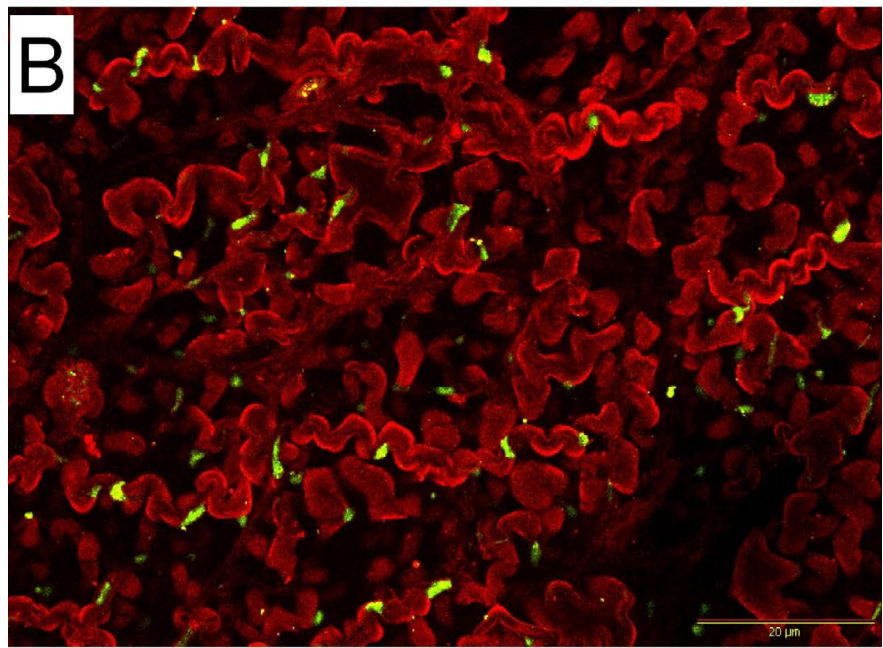

\section{centre}

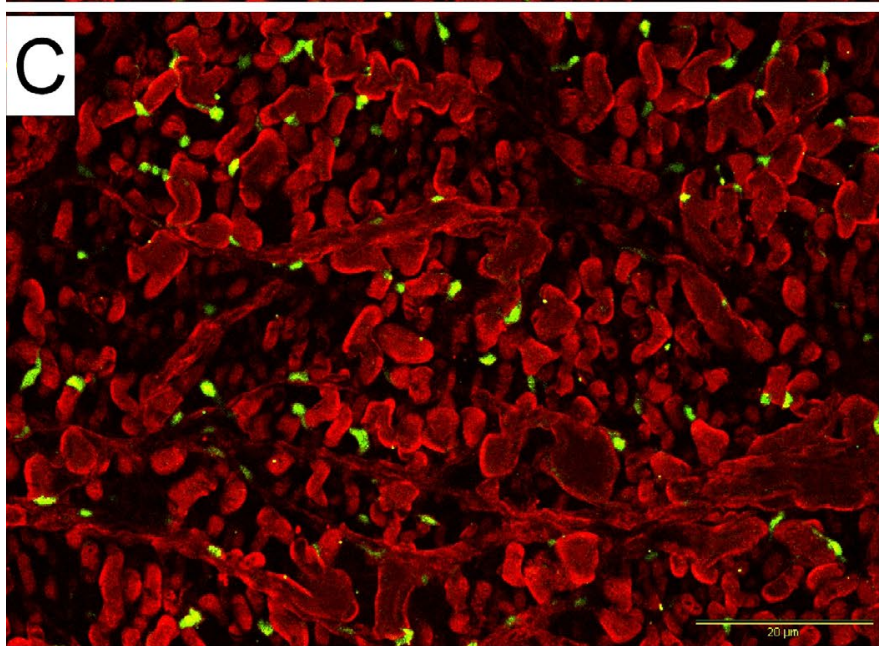

outer

fact, in cross section, they appear as wedge-shaped and slightly concave on the femoral surface and have a thick external region. Together, the two menisci cover about twothirds of the tibial plateau. The menisci are held in position through the attachments to the joint capsule and ligaments surrounding the knee (Bland-Sutton, 1897; King, 1936; Setton et al., 1999; Renstrom and Johnson, 1990). These attachments maintain correct positioning of the meniscus during radial and anteroposterior displacement of the knee and provide crucial blood supply to the peripheral regions of the meniscus.

Unlike the articular cartilage, the menisci possess an intrinsic innervation, which is related to joint proprioception (O’Connor and McConnaughey, 1978; Wilson et al., 1969). It is scarce in the body region but well represented in the anterior and posterior horns. It has been postulated that they are activated during flexion and extension of the knee, providing the central nervous system with information regarding joint position thus contributing to a reflex arc that stimulates protective or postural muscular reflexes (O'Connor and McConnaughey, 1978; O'Connor, 1984). Regarding vascularisation, the human medial meniscus is vascularised in the outer 10$30 \%$, while the lateral meniscus is vascularised in only the outer 10-25\% of its width (Arnoczky and Warren, 1982). These vascularised outer regions have greater propensity 


\section{Radial fibres Irregular superficial fibres}

Fig. 2. Schematic diagram of the ultrastructure of collagen fibres of the meniscus. The large collagen fibres on the interior of the tissue have a predominant circumferential orientation. The fine fibres of the surface layer have no preferred orientation. Within the interior of the meniscus are radially oriented collagen "tie" fibres.

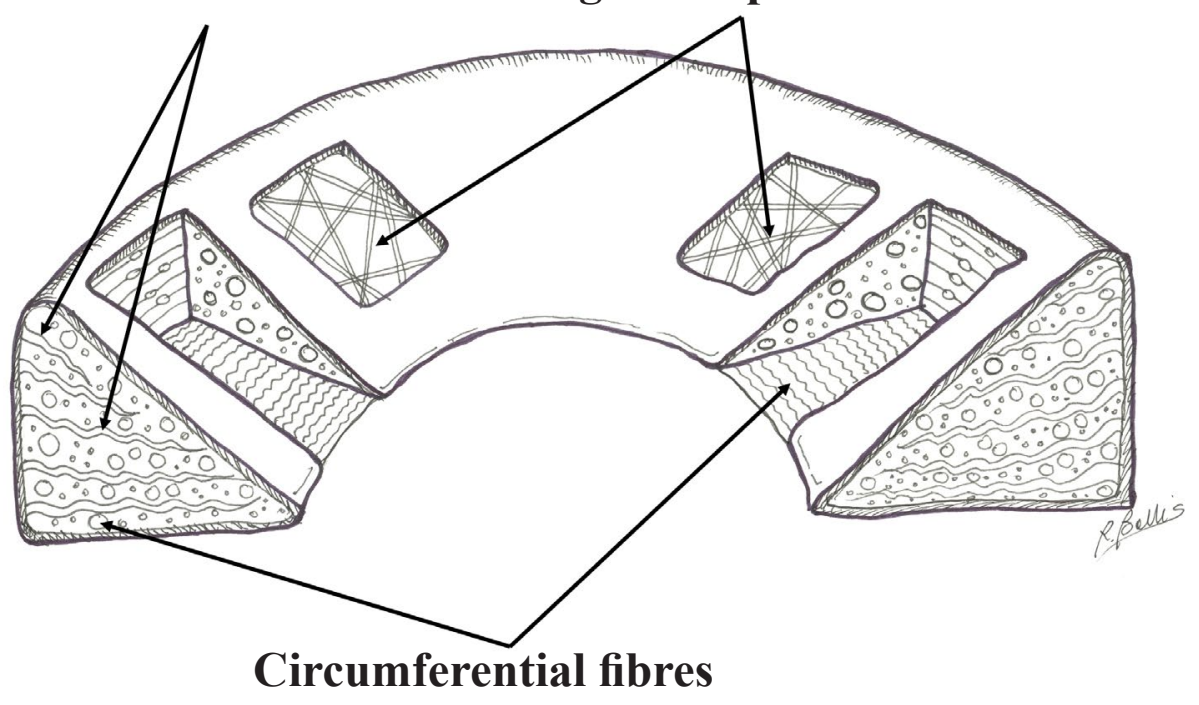

to heal when stabilised with sutures or anchors than the inner avascular regions. At the microvascular level, a capillary plexus that originates in the joint capsule and synovial tissues surrounding the joint supplies the menisci (Arnoczky and Warren 1982; Renstrom and Johnson, 1990; Cooper et al., 1990; Cooper et al., 1991). Additionally, the limited vascularity of the meniscus probably has a negative effect on the ability to recruit cells to a lesion for normal wound repair. This may be especially true for the nonvascular inner regions. Regarding biochemical composition, about $70-75 \%$ of the wet weight of the meniscus consists of water (Arnoczky et al., 1988; Adams and Hukins, 1992; Ghosh and Taylor, 1987; McDevitt and Weber, 1990). The dry weight is comprised of 60-70\% collagen, $1 \%$ proteoglycans, and $8-13 \%$ non-collagenous proteins such as elastin. Collagens are primarily type I (90\%) (Fig. 1) with smaller amounts of II, III, V, and VI (Adams and Hukins, 1992; McDevitt and Weber, 1990). The collagen fibres are predominantly oriented circumferentially, with some radially oriented fibres (Fig. 2). This may be related to the mechanical forces which act on the menisci. At the meniscal surface, a collagen fibrillar network, woven into a mesh-like matrix, has been identified. The meniscus has elastin fibres throughout that bridge the collagen fibres. There are also inhomogeneities in tissue composition from the peripheral vascular regions to the inner avascular regions. This is appreciated by the histological appearance of the inner portion that resembles articular cartilage, whereas the outer portions are more fibrocartilage-like. Similarly, the superficial portion of the meniscus has an appearance similar to fibrous tissues. Regarding cell types, cells in the superficial layers of the tissue are fusiform, whereas those located in the deeper zones are more polygonal. Cell morphology also changes from the inner avascular region, where the cells are nearly indistinguishable from articular chondrocytes, to the outer vascular regions, where the cells are more fibroblast-like. Although the cells share many morphologic similarities to articular chondrocytes, they predominantly produce type I collagen. Thus, the cells are most often referred to as fibrochondrocytes and have a complex developmental origin (McDevitt et al., 1992; Hyde et al., 2008).

In all, the material properties of the various regions of the meniscus are determined largely by the composition and microstructure of the tissue. These properties are highly anisotropic and different in compression and tension. They also vary considerably, depending on the depth and circumferential location of the force in the tissue (Mow et al., 1992). Approximately $50 \%$ of the compressive load is transmitted through the menisci as the knee goes to extension, while the load can increase to as much as $85 \%$ in flexion (Ahmed and Burke, 1983). In humans, the medial meniscus bears about $50 \%$ of load whereas the lateral meniscus bears as much as $70 \%$ (Walker and Erkman, 1975). Under normal physiologic loading, the meniscus experiences large tensile and shear stresses as well as compressive stress. Under loaded conditions the meniscus is not only subjected to a vertical force to the inner portions, but there is also a radially directed force applied to the concave surface pushing the meniscus outward (King, 1936, Shrive et al., 1978). These high mechanical requirements make the meniscus a crucial player in knee homeostasis and represent the rationale for a regenerative approach to meniscal lesions.

\section{Meniscal lesions}

In the early years of meniscal surgery, it was the gold standard to entirely excise the injured meniscus. Since then, after recognising that a total or subtotal meniscectomy inevitably leads to development of osteoarthritis within 5-10 years after surgery, it was advocated that as much meniscus tissue as possible should be preserved (McGinity et al., 1977). Only the meniscus tissue which is identified as unrepairable should be excised (McGinity et al., 1977). As a matter of fact, during the last decades, profound knowledge of the meniscus function has been established (Wojtys and Chan, 2005) and the importance of the integrity of the menisci for the homeostasis of the knee joint has been recognised and highlighted by a number of clinicians and researchers (Dye, 1996; Arnold et al., 2012). 

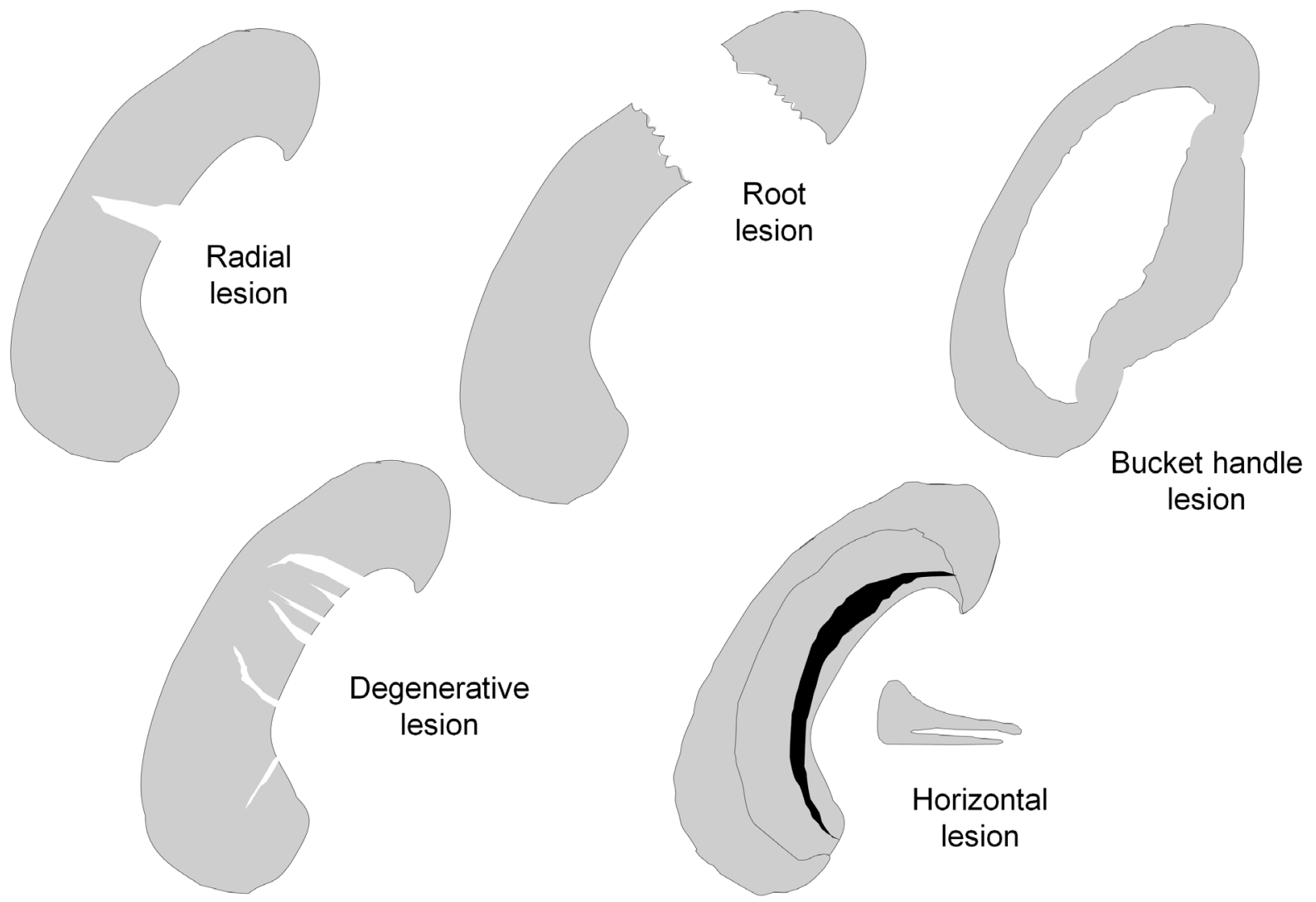

Fig. 3. Schematic diagram of different types of meniscal lesions.

In children, meniscal lesions are typically due to trauma or more frequently due to congenital meniscal variants such as a discoid meniscus or meniscal cysts (Hirschmann and Friederich, 2009). In adults, meniscal lesions are due to trauma, degenerative disease or a combination of both (Pujol and Boisrenoult, 2009; Verdonk and Verfevre, 2009). In contrast to meniscal lesions in children, in adults the meniscal injuries, which predominantly involve the medial meniscus, are often associated with concomitant ligament or cartilage lesions (Pujol and Boisrenoult, 2009; Verdonk and Verfevre, 2009). In addition, the lesion itself is more complex in adults, as the meniscus undergoes a significant degeneration in the course of a lifetime (Pujol and Boisrenoult, 2009). Not surprisingly, there is an increase of the incidence of meniscal lesions with increasing age (Pujol and Boisrenoult, 2009).

The meniscal injuries can be classified with regards to the tear pattern in radial, longitudinal, horizontal, circumferential, and root lesions (Fig. 3) (Hirschmann and Friederich, 2009). It is believed that the central $1 / 3$ of the meniscus (white zone) has less healing potential than the middle (red-white zone) and the peripheral $1 / 3$ (red-red zone) (Hirschmann and Friederich, 2009).

\section{Current surgical treatments}

The treatment of meniscal lesions has evolved tremendously during the last decades. Numerous techniques and methods have been established in patients with meniscal lesions (DeHaven, 1990). A considerable number of patients with traumatic or degenerative meniscal lesions can be treated non-operatively. In fact, this is true for all patients who do not present with (i) blocking of the knee joint, (ii) pain non-responsive to pharmacological treatment, and (iii) meniscal lesions that appear to be biomechanically unstable. In this situation, the meniscus lesions could be masterly neglected. Typically, these lesions include partial thickness tears $(<5 \mathrm{~mm})$, short radial tears $(<5 \mathrm{~mm})$ and short full thickness vertical or oblique tears $(<5 \mathrm{~mm})$. Some authors also prefer non-surgical treatment for most of the lateral meniscal lesions.

Nowadays, a subtotal or total meniscectomy, whether open or arthroscopically, is only rarely performed, which can be attributed to the increasing awareness of the deleterious effect of meniscus removal (Fairbank, 1948; DeHaven, 1985; Noble and Turner, 1986). Thus, it is spared for patients with unrepairable, complex, mostly degenerative meniscus lesions (Noble and Turner, 1986). A partial medial or lateral meniscectomy often becomes necessary in symptomatic patients. Along with the increasing interest in meniscus preserving techniques and unconvincing results in partially meniscectomised patients, numerous meniscal repair procedures have been advocated (Rodkey et al., 2008; Han et al., 2010). Generally, these can be differentiated as inside-out, outside-in and all-inside repairs (Steenbrugge et al., 2004; Majewski et al., 2009; Hoffelner et al., 2011). A young patient age and recent injury are common indications for meniscal repair, but only lesions located in the vascular zone of the meniscus can be repaired. However, even in older patients and older meniscal lesions, many surgeons believe that a repair of the meniscus is of clinical benefit and thus should be attempted.

To date, all-inside fixation devices can be considered as a valuable option for most of the patients with repairable meniscal lesions (Hoffelner et al., 2011). Inside-out and 
outside-in repair are good treatment alternatives for selected patients, in particular meniscal lesions in the anterior horn or corpus (Steenbrugge et al., 2004; Majewski et al., 2009). Importantly, although these repair devices have evolved, failure still does occur (Katabi et al., 2009).

Aiming for improved healing of the meniscus, several different methods, including very basic ones, such as needling, abrasion, trephination and gluing, or more complicated ones, such as synovial flaps, meniscal wrapping or the application of fibrin clots, have been proposed (Jacobi and Jakob, 2009; Longo et al., 2012; Scordino and Deberardino, 2012).

\section{Clinical need for regenerative strategies}

Generally, a more active lifestyle in the younger but also older age group puts knees at a higher risk for sustaining a meniscal injury (Hirschmann and Friederich, 2009). All age groups and in particular children increasingly participate in more extreme, competitive or even professional sports (Hirschmann and Friederich, 2009). The consequence of this fact is that meniscal surgery is performed at a younger age, and less meniscus tissue is preserved for a longer lifetime period. In young, active patients a partial medial meniscectomy may be the starting point for a disturbed homeostasis of the knee, even if the mechanical axis is only slightly varus aligned (Arnold et al., 2012). This altered knee homeostasis and increased loading then inevitably leads to the development of osteoarthritis, which should be prevented under all circumstances. There is therefore a clear need for regenerative strategies in these young and middle aged patients (Arnold et al., 2012). This is where orthobiologic treatments come into play. The orthobiologic treatment algorithm is defined by a distinct hierarchy: (i) neutral leg alignment, (ii) ligamentous stability, (iii) meniscus integrity, and (iv) cartilage restoration. Each of these concepts is crucial to restore knee homeostasis (Arnold et al., 2012).

In the last decade, striving for optimal restoration of meniscal tissue, the orthopaedic surgeon`s armamentarium has been enriched by the use of biocompatible meniscus scaffold and meniscal allograft transplantation (Efe et al., 2012; Monllau et al., 2011; Zaffagnini et al., 2011; Harston et al., 2012). Some authors also even recommend a meniscal substitution for young athletes after meniscectomy, independent of their symptoms (Efe et al., 2011; Monllau et al., 2011; Zaffagnini et al., 2011; Harston et al., 2012). However, despite promising short-term results, none of the current strategies have demonstrated regeneration of a functional, long-lasting meniscal tissue and re-establishment of a proper knee homeostasis in the meniscectomised knee.

\section{Cell-free techniques}

The rationale for using a cell-free biomaterial to replace part of the meniscus is based on repopulation of the scaffold by the host cells recruited from the synovium and the meniscal remnants, and subsequent tissue ingrowth which renders this approach cell-based after implantation. A mandatory prerequisite is the absence of both knee instability and malalignment. In addition, meniscal substitutes are not indicated in case of radial tears since their implant would require extensive tissue resection.

The collagen meniscus implant (CMI) (ReGen Biologics, Franklin Lakes, NJ) is the first regenerative technique applied to meniscal tissue in clinical practice (Stone et al., 1992; Stone et al., 1997; Steadman and Rodkey, 2005; Zaffagnini et al., 2007). Since an outer rim of meniscal tissue is needed for CMI implantation, it is indicated only for partial and not total meniscus regeneration. Satisfactory clinical results have been reported (Rodkey et al., 1999), while MRI and histological results are controversial: (i) the CMI shrinks over time; (ii) it showed no histological remnants 5 to 6 years after implantation (Steadman and Rodkey, 2005); and (iii) it predominantly generates a scar tissue instead of fibrocartilage (Martinek et al., 2006). In a recent mediumterm follow-up, non-controlled case series involving 34 patients, Bulgheroni et al. (2010) showed good to excellent clinical results after 5 years from a CMI implantation for a symptomatic deficiency of medial meniscal tissue. In particular, chondral surfaces had not further degenerated after placement of the CMI, and MRI signal had indicated a progressive maturation between 2 and 5 years after implantation, progressively resembling the low signal of a normal meniscus. Authors confirmed the tendency of the CMI-new tissue complex of undergoing shrinking, but with no generally negative effects on the clinical outcome. Another non-controlled case series reported significant pain relief and functional improvement at a minimum 10-year follow-up (Monllau et al., 2011). However, no negative controls were included in these two studies, making it difficult to ultimately assess the value of this procedure. Overall, despite the wide clinical use, no randomised, highquality controlled trial supports the use of this implant.

Following several experimental studies in animal models for total meniscus replacement (van Tienen et al., 2009; Welsing et al., 2008; Hannink et al., 2011), polyurethanes are now being assessed as alternative biomaterials for partial meniscus replacement. The Actifit ${ }^{\mathrm{TM}}$ (Actifit, Orteq Ltd, London, United Kingdom) meniscus implant is a polyurethane-polycaprolactone (PU-PCL)based synthetic meniscal substitute intended for use in the irreparable, partial meniscal defects (Verdonk et al., 2009; Verdonk et al., 2011). Because of its polymeric nature, Actifit $^{\mathrm{TM}}$ has a higher mechanical strength and ease of handling compared to CMI. On the other hand, degradation is expected to occur in 4 to 6 years, thus being much slower than that of CMI. In particular, polycaprolactone is degraded by hydrolysis while polyurethane is slowly degraded by macrophages and giant cells. The clinical application of this meniscal implant started recently and medium to long-term evidence on chondroprotection is not yet available. The first 12-month report of a multicentre, prospective clinical trial involving 52 patients with irreparable meniscal tear or partial meniscal loss has been recently published, showing tissue ingrowth into the scaffold at 3 months and further tissue ingrowth at 12 months, with consistent MRI and histology data (Verdonk et al., 2011). Another recently published study, involving 10 patients with a 12-month follow-up, showed the safety 
of this scaffold for the treatment of symptomatic patients with segmental medial meniscus defects. (Efe et al., 2012). However, only when more medium-to-long term evidence about its safety and effectiveness will be available, could Actifit $^{\mathrm{TM}}$ be considered a valid alternative for partial meniscal replacement.

In conclusion, meniscal implants demonstrated good short- to medium-term clinical results, but no evidence supports their use routinely in clinical practice and no study reported convincing long-term protection from joint degeneration to date.

\section{Meniscal transplantation}

Meniscus represents the ideal tissue for transplantation: vascular anastomosis is not needed and its cells are immunoprivileged because of the avascular environment. As a consequence, surgery is less demanding and immunosuppressive therapy is not needed (Jackson et al., 1992). Meniscal transplantation is actually the only biologic option available for the symptomatic, totally meniscectomised, non-osteoarthritic, stable and wellaligned knee (Verdonk et al., 2007; Lubowitz et al., 2007). On the other hand, although this technique is not new (Milachowski et al., 1989), the long-term effects, especially in terms of chondroprotection and prevention of osteoarthritis, still remain to be proven (Wirth et al., 2002). Limitations of this procedure include tissue availability, risk of immune reaction, risk of disease transmission, and graft sizing (Lubowitz et al., 2007).

Regarding the type of allograft, four have been used: cryopreserved, deep-frozen (fresh-frozen), fresh, and lyophilised (freeze-dried) (Cole et al., 2003; Lubowitz et al., 2007). Fresh grafts present the advantage of being rich in viable cells and this has been demonstrated to improve mechanical integrity following transplantation, determining a lower failure rate of the procedure compared to those of deep-frozen and lyophilised grafts (Siegel and Roberts, 1993; Verdonk et al., 2005). Despite this advantage, no evidence supports the increased expense related to these procedures (Verdonk et al., 2005; Lubowitz et al., 2007). Moreover, an animal study demonstrated that donor cells are replaced by host cells, so that the need of a viable graft has been questioned (Jackson et al., 1993). However, donor DNA remains detectable in human patients for a longer period than in the animal models (Verdonk et al., 2005).

According to current literature, indications to this technique are not yet defined; however, it seems to be indicated in two clinical scenarios (Verdonk et al., 2007; Lubowitz et al., 2007): (i) young patients ( $<50$ years of age) with a symptomatic, meniscus-deficient compartment in a stable joint, without malalignment and with only minor chondral lesion (no more than grade 3 according to ICRS score); and (ii) patients with an ACL-deficient knee which sustained a medial meniscectomy. In the second group of patients, meniscal transplantation is performed together with ACL reconstruction as it grants an improved stability compared to that obtained with ACL reconstruction alone (Barber, 1994). A further clinical scenario has been advocated by some authors (Johnson and Bealle, 1999): prophylactic transplantation in young, sportive patients who had complete meniscectomy, before the onset of symptoms. However, such an aggressive approach is not routinely recommended to date (Lubowitz et al., 2007).

A recently published meta-analysis, analysing 44 published clinical trials with at least 6 months follow-up in the last 26 years, concluded that this procedure should not be considered experimental surgery anymore, but, instead, it is a safe and effective technique allowing patients to resume high levels of activity and work, at least, as a longterm "bridging" procedure before arthroplasty (Elattar et al., 2011). Actually, a number of orthopaedic surgeons have reported clinical and radiological mid-term results (Kim et al., 2012; Lee and Caborn, 2012). However, fixation of the allograft, whether soft-tissue or bone plug associated, remains a significant source of failure (Hommen et al., 2007). Additional problems of meniscal allograft transplantation are the limited availability, the technically demanding surgical procedure, and the frequent mismatch of graft and host tissue (Shaffer et al., 2000). Xenografts have only been used in animal or cadaver studies till now, but might become an interesting treatment alternative (Jiang et al., 2012).

In conclusion, meniscal transplantation allows for good short-to-intermediate term results in selected patients, while it is not yet demonstrated whether this technique provides long term protection from joint degeneration (Wirth et al., 2002).

\section{Research potential for meniscus repair and regeneration: from cell therapy to tissue therapy}

Currently, a number of experimental approaches are addressing the issue of meniscal regeneration. In particular, researchers work on the development of different potential regenerative solutions for different clinical scenarios requiring different surgical treatments. These can be summarised as follows: (i) improved biological bonding in case of reparable tears; (ii) partial meniscus regeneration, to restore the tissue removed after meniscectomy; and (iii) total meniscus regeneration, when sub- or total meniscectomy is performed. In the following sections the mainstays of tissue engineering (cells, growth factors and scaffolds), with respect to meniscus regeneration, and the experimental strategies combining them will be reported.

\section{Cell sources}

Several adult differentiated cells from various tissues have been used in tissue engineering studies. In this chapter, we will discuss the potential for meniscus regeneration of meniscus cells (MC), articular (AC), costal (CC) and nasal chondrocytes (NC), bone marrow-derived mesenchymal stem cells (MSC), synovial membrane-derived MSC and embryonic stem cells (ESC).

From a clinical standpoint, the ideal tissue for cell harvesting is the meniscectomised meniscus itself, as no additional morbidity is produced. Nakata et al. (2001) investigated the potential for tissue engineering approaches of $\mathrm{MC}$ isolated from meniscectomised menisci. In this study, authors expanded in vitro human MC and seeded them on a collagen scaffold with success, demonstrating 
the feasibility of obtaining an adequate number of cells from small meniscal specimens and of seeding them on biologic scaffolds. In a more recent study, Baker et al. (2009) demonstrated that expansion and seeding of meniscal debris-derived cells onto nanofibrous scaffolds led to engineered constructs with mechanical properties in tension approaching native tissue levels. However, many patients candidate to meniscus allotransplantation have already undergone total meniscectomy and an alternative cell source is, therefore, needed. This feature limits the use of this cell type only to meniscus repair and regeneration approaches.

Articular cartilage is an attractive cell source also for meniscus tissue engineering since it can be easily harvested from non-weight bearing areas and $\mathrm{AC}$ can be enzymatically isolated and used for tissue engineering strategies. Marsano et al. (2007) investigated and compared the potential for meniscus tissue engineering of inner meniscus cells, fat pad cells, synovial membrane cells and AC in pellet culture, in scaffold, and in nude mice culture. The authors reported the formation of meniscus-resembling tissue by AC only, while in the samples obtained with the other cell types, the glycosaminoglycan (GAG) content was negligible and no collagen type II was detected. This is consistent with all the previous works reporting the $\mathrm{AC}$ capability of accumulating large quantities of cartilaginous matrix. Interestingly, AC deposited also collagen type I and $\mathrm{IV}$, the latter typically present in the outer vascularised area of the meniscus. In addition, the phenotype of AC may adapt upon exposure to specific regimens of physical forces in order to generate a tissue structure resembling that of the human meniscus (Marsano et al., 2006), making them an attractive cell type for meniscus tissue engineering.

Interest has recently focused on the potential of $\mathrm{CC}$ for knee and temporomandibular joint meniscus tissue engineering (Johns and Athanasiou, 2008; Anderson and Athanasiou, 2009). Importantly, costal cartilage represents a clinically-compliant cell source since the harvest can be abundant while leaving little donor site morbidity. These cells display also a high synthetic activity after in vitro expansion, being able to deposit large quantities of fibrocartilaginous matrix with GAGs, collagen type II and type I (Johns and Athanasiou, 2008). This feature can be further manipulated by co-culturing $\mathrm{CC}$ with other cell types in order to create a spectrum of fibrocartilaginous engineered tissues. In particular, the collagen I/II ratio could be modified by cell types used in co-culture and serum presence in order to span the whole native range (Hoben and Athanasiou, 2008).

Thanks to their high chondrogenic potential, ease of harvesting, lower inter-individual variability, faster proliferation and positive response to load, NC have been extensively studied for cartilage tissue engineering purposes (Scotti et al., 2012; Candrian et al., 2008; Tay et al., 2004). In particular, their capability to adapt to a joint-like environment (low-oxygen tension, inflammatory environment and load) makes them a suitable cell source for joint regeneration (Scotti et al., 2012; Candrian et al., 2008). However, to date there is no report in the literature of NC-based approaches for meniscus regeneration.
Stem cells are characterised by self-renewal capacity and multilineage differentiation potential to distinctive end-stage cell types of mesenchymal tissues, such as bone, cartilage, muscle, tendon/ligaments and fat, in response to environmental cues (Caplan, 1991; De Bari et al., 2007). They can be extensively expanded in vitro while maintaining their differentiation potential and subsequently cryopreserved. In addition, MSC have a natural capacity to home to injured tissues and to participate to tissue healing. This second feature seems particularly interesting as MSC not only provide a substrate for regeneration but also secrete paracrine factors that enhance the potential for tissue repair, acting as "trophic mediators" (Caplan, 2007). MSC have been isolated from several tissues, including bone marrow (Pittenger et al., 1999), periosteum (De Bari et al., 2001a), synovial membrane (De Bari et al., 2001b) and adipose tissue (Zuk et al., 2002).

Bone marrow is the main cell source for adult MSC because of its ease of harvest with limited morbidity and, therefore, MSC have been used in a myriad of experimental studies and also in some clinical trials. Adult bone marrow contains both haematopoietic stem cells (HSC) and MSC (Caplan, 1991; Herzog et al., 2003). HSC and MSC can be distinguished by the expression of cell surface antigens, as MSC typically lack antigens such as CD45 and CD34 that usually identify HSC (Herzog et al., 2003). However, the number of progenitor cells present in human fresh bone marrow biopsies is very low (about $0.01 \%$ of the total mononucleated cells), further decreasing with donor age and thus requiring in vitro cell expansion to reach an adequate cell number for regenerative purposes (Muschler et al., 2001). Another possible drawback of bone marrow-derived MSC, limited to articular cartilage and meniscus regenerative strategies, is that they seem to retain osteogenic propensities, through an endochondral pathway, as the default differentiation route (Muraglia et al., 2000; Scotti et al., 2010). As a consequence, chondrocyte hypertrophy and subsequent vascularisation and mineralisation can impair the final quality of the newly formed tissue. However, bone marrow-derived MSC still remain the mainstay of stem cell-based approaches in orthopaedic clinical practice.

Another attractive cell source for the orthopaedic surgeon is represented by the synovial membrane, since it can be easily harvested in both open and arthroscopic surgery. Synovial membrane-derived MSC have been described by De Bari et al. (2001b) reporting a progenitor nature with remarkable self-renewal capacity. Recently, work has described the superior capacity of synovial membrane-derived MSC to generate cartilaginous tissues compared to MSC obtained from other tissues (Sakaguchi et al., 2005). On the other hand, a following report of De Bari et al. (2004) showed that these cells failed to produce in vivo a stable and differentiated cartilaginous tissue, undergoing cell death and neoangiogenesis. This suggests that in vitro pre-differentiation is not sufficient to guarantee stable lineage commitment and restriction of differentiation. However, synovial membrane-derived MSC are still a valuable and promising cell type for tissue engineering, and different approaches, such as intraarticular delivery, are currently being investigated. 
The use of ESC is also advocated for meniscus tissue engineering strategies (Koay and Athanasiou, 2009; Hoben et al., 2008). Despite the concerns raised about ethical issues, their safety, since they tend to form tumours once implanted unless they are pre-differentiated, and since they are immunogenic, their highly pluripotency makes them an attractive cell type for the regeneration of various tissues (De Bari et al., 2007). While the issue of the oncogenic potential is currently being addressed by improving in vitro ESC commitment and culture, the immunogenicity could be overcome by implementing large cell banks with genotyped ESC cell lines (De Bari et al., 2007). This would theoretically allow transplanting a large number of HLAmatched recipients with these cells. However, a possible clinical application of ESC for non-lethal diseases is still to be planned.

\section{Intra-articular delivery of MSC}

An attractive strategy for joint regeneration is intraarticular injection of progenitor cells that can participate to and enhance tissue regeneration. This approach presents several advantages: (i) it is easy to be performed in an outpatient setting with minimum morbidity; (ii) it can be used to deal with either single lesions or degenerative diseases; (iii) it works in two directions, delivering cells that can both actively regenerate the damaged tissues and secrete anti-inflammatory and trophic factors that can reestablish joint homeostasis according to Caplan (Caplan, 2007; Caplan and Correa, 2011); (iv) it can be repeated; and (v) it minimises systemic diffusion of the implanted cells (Horie et al., 2009).

A first report of this strategy has been performed by Murphy et al. (2003) by injecting bone marrow-derived MSC in suspension with sodium hyaluronan in an osteoarthritis (OA) goat model. In this work, the authors showed successful cell survival and engraftment in the regenerated medial meniscus which was completely excised, together with the ACL, to determine OA. Importantly, this involvement of the injected MSC in the regenerated meniscus resulted in protection from OA progression at the latest experimental time point. However, the number of injected cells in the regenerated tissue was too low for being responsible of the massive tissue regeneration, while, on the other hand, MSC had more likely trophically enhanced the regeneration of the meniscus.

In a more recent work, Horie et al. (2009) investigated the potential for meniscus regeneration of intra-articularly injected synovial membrane-derived MSC in a rat massive meniscal defect model. The authors not only demonstrated active participation of the injected MSC in the regeneration process, adhering to the injured sites and synthesising new tissue, but also showed with in vivo imaging analysis that the injected cells do not mobilise out of the injected joint. This is a crucial safety issue with respect to a possible clinical application of this approach. Another interesting finding in this work is that the authors could detect MSC activity in the knee joint up to $28 \mathrm{~d}$ after the injection but not at a longer time point. This can be explained by the fact that, after triggering tissue regeneration, most cells die while only a few remain in the newly formed tissue. This is further evidence supporting the hypothesis of MSC as trophic factor releaser for tissue repair. However, stronger evidence, possibly obtained with more relevant large animal models, should be provided prior to considering this approach as an option with clinical relevance.

\section{Growth factors and gene therapy}

To date, the effect of many growth factors (GF) on meniscal fibrochondrocytes or meniscal explants has been investigated (Table 1), since matrix synthesis enhancement and metalloproteinase inhibition are crucial mechanism to be addressed for meniscus repair and tissue engineering (Buma et al., 2004). In particular, transforming growth factor $\beta$ (TGF- $\beta$ ) demonstrated a promising effect in term of stimulation of GAGs and biglycan production by MC in vitro (Collier and Gosh, 1995). However, it remains to be demonstrated whether TGF- $\beta$ stimulation may lead to a tissue engineered meniscus more similar to native meniscus or to a more efficient repair, because collagen, rather than GAGs, seems to be important for meniscus function (Buma et al., 2004). Other GF demonstrated to have a trophic effect on meniscal fibrochondrocytes are: hepatocyte growth factor (HGF); insulin-like growth

Table 1. Growth factors of relevance for meniscus tissue engineering.

\begin{tabular}{|c|c|c|}
\hline Growth factor & Effect on meniscal cells or tissue & References \\
\hline FGF-2 & $\begin{array}{l}\text { Enhance cell proliferation in monolayer cultures } \\
\text { Enhance collagen synthesis in cell-seeded scaffold }\end{array}$ & $\begin{array}{l}\text { (Marsano et al., 2007) } \\
\text { (Pangborn and Athanasiou, 2005) }\end{array}$ \\
\hline TGF- $\beta 1$ & $\begin{array}{l}\text { Enhance cell proliferation in monolayer culture } \\
\text { Enhance SMA expression } \\
\text { Enhance collagen and proteoglycan synthesis } \\
\text { Enhance cell proliferation on a PU scaffold }\end{array}$ & $\begin{array}{l}\text { (Marsano et al., 2007) } \\
\text { (Zaleskas et al., 2001) } \\
\text { (Collier and Ghosh, 1995, Pangborn and Athanasiou, 2005) } \\
\text { (de Mulder } \text { et al., 2011) }\end{array}$ \\
\hline IGF-1 & $\begin{array}{l}\text { Main anabolic factor of cartilage } \\
\text { Enhance collagen synthesis in cell-seeded scaffold } \\
\text { Stimulate cell migration }\end{array}$ & $\begin{array}{l}\text { (Buma et al., 2004) } \\
\text { (Pangborn, 2005) } \\
\text { (Bhargava et al., 1999) }\end{array}$ \\
\hline HGF & Improve vascularisation of engineered tissue & (Hidaka et al., 2002) \\
\hline PDGF-BB & $\begin{array}{l}\text { Enhance cell proliferation in vitro } \\
\text { Decrease SMA expression }\end{array}$ & $\begin{array}{l}\text { (Marsano et al., 2007) } \\
\text { (Zaleskas et al., 2001) }\end{array}$ \\
\hline $\begin{array}{c}\text { BMP-2 } \\
\text { BMP-7 (OP-1) }\end{array}$ & $\begin{array}{l}\text { Enhance cell proliferation } \\
\text { Stimulate cell migration } \\
\text { Enhance proteoglycan synthesis }\end{array}$ & $\begin{array}{l}\text { (Bhargava et al., 1999) } \\
\text { (Bhargava et al., 1999) } \\
\text { (Lietman et al., 2003) }\end{array}$ \\
\hline
\end{tabular}


factor 1 (IGF-1); fibroblast growth factor 2 (FGF-2); platelet-derived growth factor (PDGF); and certain bone morphogenetic proteins (BMPs) (Buma et al., 2004, Pangborn and Athanasiou, 2005). In particular, HGF was demonstrated to enhance vascularisation of engineered meniscal fibrochondrcyte-PGA constructs, but without improving mechanical properties (Hidaka et al., 2002), and IGF-1 is one of the main anabolic factors of articular cartilage (Schmidt et al., 2006). As the outer part of the meniscus is vascularised (Clark and Ogden, 1983) and the inner region is characterised by an ECM partially similar to that of the articular cartilage (Chevrier et al., 2009), the use of these two GF could be a promising combination to be evaluated. Another interesting finding was the modulation of smooth muscle actin (SMA) expression by TGF- $\beta 1$ and PDGF-BB (Buma et al., 2004). A study demonstrated that TGF- $\beta 1$ increases SMA expression and cell contraction while PDGF-BB has the opposite effect: investigation of the mechanisms underlying SMA-enabled contraction may be crucial for cell expansion and differentiation (Zaleskas, 2001).

Recent advances in gene therapy techniques have demonstrated the feasibility of gene transfer to musculoskeletal tissues (Evans and Robbins, 1999; Madry et al., 2003; Madry et al., 2004). GF gene transfer is an attractive option to enhance meniscal repair, and this has been demonstrated both in vivo and in vitro with different approaches (Goto et al., 1999; Hidaka et al., 2002; Martinek et al., 2002; Nakata et al., 2001). Several vectors have been used: retroviral, adenoviral and adenoassociated; each of them presenting peculiar characteristics (Madry et al., 2004; Goto et al., 1999; Hidaka et al., 2002). Retroviral vectors have been widely used in gene therapy studies, nevertheless they need actively replicating cells as target, while fibrochondrocytes do not duplicate in vivo, and they can theoretically cause cancer, through insertional mutagenesis. Although the first limitation can be overcome by the use of lentiviral vectors, that can transduce also non-dividing cells, safety concerns make them unattractive to orthopaedic researchers who deal with non-lethal disorders (Madry et al., 2004; Daniel and Smith, 2008). Adenoviral vectors are immunogenic and do not integrate into the host cell genome; as a consequence they prevent the risk of cancer but they do not grant longterm transgene expression (Madry et al., 2004; Steinert et al., 2007). Adeno-associated vectors (AAV) can carry only a small amount of DNA; on the other hand, they are not immunogenic and not pathogenic, and they can transduce non-dividing cells: these features make them very attractive for orthopaedic use, making them a promising option for the treatment of musculoskeletal diseases (Madry et al., 2004; Cucchiarini et al., 2009).

Following the first studies with marker genes (Madry et al., 2004; Goto et al., 1999), the main GF used for gene transfer to the meniscus to date are HGF (Hidaka et al., 2002), TGF- $\beta 1$ (Steinert et al., 2007), and FGF-2 (Cucchiarini et al., 2009). HGF induced blood vessel formation in an engineered construct made of meniscal fibrochondrocytes seeded onto a PGA scaffold, improving the potential for integration and metabolic exchanges of the engineered implant (Hidaka et al., 2002). TGF- $\beta 1$ gene transfer enhanced the cellularity and the deposition of proteoglycans and collagen type 2 both in monolayer and in 3D cultures (Steinert et al., 2007; Goto et al., 2000). On the other hand, of importance are the consequences of ubiquitous overexpression of TGF- $\beta 1$, as it determines severe joint fibrosis and detrimental systemic effects (Mi et al., 2003; Steinert et al., 2007). Consequently, a localised delivery of TGF- $\beta 1$ to the site of lesion is mandatory. FGF-2 transfer through an AAV resulted in increased proliferation, survival and metabolic activity of human $\mathrm{MC}$ in vitro, in a three-dimensional in vitro culture system, and in situ in a human meniscal defect model (Cucchiarini et al., 2009). This study proved that direct application of AAV vectors has the potential to induce healing in the injured meniscus. However, since no complete healing was achieved and since proliferation is just one player of tissue regeneration, additional studies are required to assess the optimal gene delivery strategy for meniscus regeneration.

Overall, the application of gene transfer techniques to meniscus regeneration holds some potential. However, several variables have to be still assessed, such as i) the modality of transduction (modification of many cell types, transduction of whole tissues, intra-articular injection); ii) the ideal combination of genes to be transferred; or iii) the most efficient cell type, when transfected cells are used.

\section{Scaffolds}

A biomaterial used as scaffold for meniscus tissue engineering purposes should present many features. In particular, the ideal meniscal scaffold should be (i) "cell-instructive", promoting cell differentiation and proliferation if cell-seeded, or cell migration if cell-free; (ii) "biomimetic", mimicking architecture, tribology and mechanical features of the native meniscus; (iii) resilient and resistant to withstand mechanical forces acting in the joint while cells produce ECM; (iv) biocompatible, not evoking any foreign-body reaction also with its degradation products; (v) slowly biodegradable allowing to be gradually replaced by biologic tissue; (vi) open, with high porosity, allowing diffusion of nutrients and catabolic substances; and (vii) easy to handle, to be sutured and to be implanted by the surgeon (Arnoczky, 1999; van Tienen et al., 2009).

With the ultimate goal of designing the ideal scaffold for meniscus tissue engineering, many biomaterials have been evaluated both natural and synthetic (Buma et al., 2004) (Table 2). Natural materials used to date are: periosteal tissue (Walsh et al., 1999); perichondral tissue (Bruns et al., 1998); small intestine submucosa (SIS) (Cook et al., 1999); acellular porcine meniscal tissue (Stapleton et al., 2008); and bacterial cellulose (Bodin et al., 2007). While these tissues have high biocompatibility, some of them cannot be employed for tissue engineering techniques as they do not allow varying structure geometry and initial mechanical properties (Buma et al., 2004). A more attractive strategy is represented by isolated tissue components as collagens and proteoglycans (Mueller et al., 1999; Pabbruwe et al., 2010). They maintain the high biocompatibility of the whole tissues while allowing to create custom-made scaffold with definite pore dimension and geometry and, consequently, biomechanical features. 
Table 2. Biomaterials of relevance for meniscus tissue engineering.

\begin{tabular}{|c|c|c|}
\hline Biomaterial & Summary of results & References \\
\hline Collagen & $\begin{array}{l}\text { CMI scaffolds seeded with autologous fibrochondrocytes. Macroscopic and } \\
\text { histological improvement of the transplants compared to cell-free CMI. }\end{array}$ & Martinek et al., 2006 \\
\hline SIS & $\begin{array}{l}\text { A cell-free SIS implant demonstrated better results than meniscectomy } \\
\text { with less cartilage damage. Another study reported the potential of SIS as } \\
\text { a scaffold to support co-culture of synovial membrane-derived MSC and } \\
\text { meniscal cells. }\end{array}$ & $\begin{array}{l}\text { Cook et al., } 2006 \\
\text { Tan et al., } 2010\end{array}$ \\
\hline PCL & $\begin{array}{l}\text { PCL scaffold with defined nanofibres alignment determines better neotissue } \\
\text { organisation and mechanical properties. }\end{array}$ & $\begin{array}{l}\text { Baker et al., } 2007 \\
\text { Baker et al., } 2010 \\
\text { Baker } \text { et al., } 2012\end{array}$ \\
\hline $\begin{array}{l}\text { Hyaluronan- } \\
\text { PCL }\end{array}$ & $\begin{array}{l}\text { Partial and total meniscus replacement, both cell-free and cell-seeded, in } \\
\text { ovine models. } 4 \text { months follow up. Good tissue ingrowth/formation. Better } \\
\text { results for cell-seeded scaffolds also in terms of chondroprotection. }\end{array}$ & $\begin{array}{l}\text { Chiari et al., } 2006 \\
\text { Kon et al., } 2008\end{array}$ \\
\hline $\begin{array}{l}\text { Polyurethane- } \\
\text { PCL }\end{array}$ & $\begin{array}{l}\text { Cell-free total meniscus implant demonstrated good integration and } \\
\text { fibrovascular tissue ingrowth in a } 2 \text {-year follow-up study in dogs. Mild } \\
\text { foreign body reaction was noticed. Not better chondroprotection compared } \\
\text { to meniscectomised knees. }\end{array}$ & $\begin{array}{l}\text { Hannink et al., } 2011 \\
\text { Welsing et al., } 2008 \\
\text { Heijkants et al., } 2005 \\
\text { Heijkants et al., } 2004 \\
\text { van Tienen et al., } 2009\end{array}$ \\
\hline PGA-PLGA & $\begin{array}{l}\text { Total meniscus PLGA implant seeded with allogeneic meniscal cells in a } \\
\text { rabbit model. Positive histological results at } 36 \text { weeks. Biochemical and } \\
\text { biomechanical improvement of the neotissue over time. }\end{array}$ & Kang et al., 2006 \\
\hline Silk & $\begin{array}{l}\text { Tri-layered silk fibrous protein scaffold seeded with human fibroblasts and } \\
\text { chondrocytes or MSC showed cell growth with aligned ECM deposition. }\end{array}$ & $\begin{array}{l}\text { Mandal et al., 2011a } \\
\text { Mandal et al., 2011b }\end{array}$ \\
\hline Carbon & $\begin{array}{l}\text { Replacement of the whole meniscus with a polyester-carbon cell-free } \\
\text { implant in a rabbit model. Better results than meniscectomised, untreated } \\
\text { knees. }\end{array}$ & Wood et al., 1990 \\
\hline $\begin{array}{l}\text { Hyaluronan- } \\
\text { gelatin }\end{array}$ & $\begin{array}{l}\text { Partial meniscus regeneration with a } 70 \% \text { HA-30 \% gelatin scaffold seeded } \\
\text { with autologous MSC in a rabbit model. Better results than with cell-free } \\
\text { scaffold. A second study showed better results for unpassaged MSC. }\end{array}$ & $\begin{array}{l}\text { Angele et al., } 2008 \\
\text { Zellner et al., } 2010\end{array}$ \\
\hline PVA & $\begin{array}{l}\text { Total meniscus replacement with cell-free implant in rabbit model with } \\
\text { 2-year follow up. Successful chondroprotection. No regeneration of } \\
\text { meniscal tissue. Concerns about long-term durability, safety and fixation } \\
\text { method. }\end{array}$ & $\begin{array}{l}\text { Kobayashi et al., } 2003 \\
\text { Kobayashi et al., } 2005\end{array}$ \\
\hline Agarose & $\begin{array}{l}\text { In vitro engineering of critically sized meniscal constructs with bovine and } \\
\text { ovine fibrochondrocytes in a mixing bioreactor. }\end{array}$ & $\begin{array}{l}\text { Ballyns et al., } 2008 \\
\text { Ballyns et al., } 2010\end{array}$ \\
\hline Scaffold-free & $\begin{array}{l}\text { Self-assembled engineered meniscal tissues, obtained with co-cultures } \\
\text { of fibrochondrocytes and MSC in ring-shaped moulds, displayed better } \\
\text { morphological and mechanical features than cell-loaded PGA scaffolds. }\end{array}$ & $\begin{array}{l}\text { Aufderheide and Athanasiou, } 2007 \\
\text { Huey and Athanasiou, } 2011\end{array}$ \\
\hline
\end{tabular}

However, these scaffolds have usually low biomechanical properties and are characterised by rapid biodegradation, thus not long enough to be completely replaced by the newly formed tissue (Buma et al., 2004).

On the other hand, polymer materials can be manufactured in custom-made shapes of any geometrical structure, porosity and biomechanical properties, according to the characteristics of the host tissue and the seeded cells. In particular, it has been shown that for optimal ingrowth and incorporation of a meniscal scaffold, macropore sizes must be in the range of 150-500 $\mu \mathrm{m}$ (Klompmaker et al., 1993). The biodegradation rate can be also modulated by acting on polymer composition. To date, the most used synthetic polymers are: polyglycolic acid (PGA) (Vacanti et al., 1991); poly(L)lactic acid (PLLA) (Freed et al., 1993); poly-(lactic-co-glycolic acid) (PLGA) (Kang et al., 2006); polyurethane (Heijkants et al., 2004; van Tienen et al., 2002); polyester carbon (Wood et al., 1990); polytetrafluoroethylene (Toyonaga et al., 1983); and polycaprolactone (PCL) (Lebourg et al., 2008). Possible drawbacks of the use of synthetic polymers for tissue engineering purposes are the low cell-adhesive properties, since they lack the cell-adhesion domains normally present on natural macromolecules, and the even mild foreign-body reaction occurring after implantation (Cao et al., 1998; Welsing et al., 2008). In order to improve biocompatibility and biodegradability of polymer scaffolds, the use of a biopolymer, such as silk fibrous protein, has been proposed (Mandal et al., 2011a; Mandal et al., 2011b).

An alternative attractive strategy is represented by the use of hydrogel materials. Their semi-liquid nature allows engineering anatomic geometries derived from medical imaging techniques, such as computed tomography or magnetic resonance, by the use of custom-printed moulds (Ballyns et al., 2008). Promising results were reported with alginate (Ballyns et al., 2010; Ballyns et al., 2008) and polyvinyl alcohol (PVA) (Kobayashi et al., 2003; Kobayashi et al., 2005). However, despite their wide implementation in cartilage tissue engineering they have been hardly utilised for meniscus engineering.

Briefly, both natural materials and synthetic polymers present peculiar advantages and disadvantages. Most importantly, no biomaterial demonstrated to be superior to the others in terms of supporting cell proliferation and 
tissue growth. No clear advantage was also evident in term of biomechanical properties suitable for implantation in the knee joint. A possible solution is represented by combining them, in order to couple the high cell-affinity and biocompatibility of natural polymers with the superior mechanical strength and ease of being tailored of synthetic polymers. This strategy has been recently evaluated in two large animal studies on partial and total meniscus tissue engineering with a hybrid material composed of PCL and hyaluronic acid (HA) with promising results (Chiari et al., 2006; Kon et al., 2008).

In the following sections we will discuss different experimental studies for partial and total meniscus engineering performed to date and having a potential clinical exploitation.

\section{Cell-based bonding studies}

As long as lesions occurring in the inner "red-white zone" and "white-white zone" do not allow a biological repair to be achieved, even after stabilisation, cell-based strategies have been evaluated in order to enhance the bonding of a torn meniscus. From a clinical point of view, a tool which can improve the results of meniscal sutures is valuable. The rationale of this approach has been validated in studies demonstrating that isolated chondrocytes, either seeded onto cartilaginous (Peretti et al., 1998; Peretti et al., 1999) and meniscal matrices (Peretti et al., 2001), PLGA scaffold using dynamic conditions (Yoo et al., 2011; or embedded in fibrin glue (Peretti et al., 2008; Scotti et al., 2009), were able to bond separate pieces together. These studies were performed ectopically, in a subcutaneous environment in a nude mouse model, which is vascularised and not subjected to weight bearing, and therefore not suitable to ultimately evaluate the value of a regenerative strategy for the knee joint. In order to test the potential of transplanted chondrocytes for use as a reparative technique in lesions involving the human knee, further studies were performed in situ in a pig model (Peretti et al., 2004; Weinand et al., 2006a; Weinand et al., 2006b). Among the animal models for meniscus regeneration studies (Deponti et al., 2013), the pig is very valuable as it has been demonstrated that the vascularisation of the porcine meniscus remains confined in the outer part of the menisci and never extends into the inner third of its structure (Peretti et al., 2004).

In the first study, an allogeneic devitalised meniscal scaffold was chosen as a carrier for autologous chondrocytes in an orthotopic pig model (Peretti et al., 2004). A onecentimetre longitudinal tear was created in the avascular portion of the medial meniscus at the junction of its inner third and outer two-thirds and the chondrocyte-seeded meniscal scaffold was inserted inside the lesion and secured by two vertical sutures. Histological evaluation demonstrated bonding tissue, resembling cartilaginous and fibrocartilaginous matrix, synthesised by the transplanted chondrocytes in samples from the experimental group. Although the repair was not uniformly complete in this study, the results were considered encouraging as good integration of the scaffold material with the native meniscus appeared to be present in numerous areas by the formation of new cartilage matrix.
According to these results, in subsequent studies the potential of different allogeneic cell sources and of Vicryl meshes as a scaffold was evaluated, in the same orthotopic model as the previous study (Weinand et al., 2006a; Weinand et al., 2006b). The rationale of using allogeneic cells of different sources is that it is unlikely to obtain a sufficient number of healthy meniscal fibrochondrocytes from an injured meniscus. Additionally, Johnson et al. (2004) showed the healing potential of auricular and costal chondrocytes suspended in fibrin polymer and placed between articular cartilage discs, demonstrating the feasibility for alternative cell types to heal cartilage. Moreover, the harvesting of autologous cells can add additional trauma to the patient, while large quantities of cartilage cells may be obtained using allogeneic chondrocytes from cadaveric sources. Regarding the results of these studies, some degree of new tissue formation was found in all experimental samples, whereas none was found in any of the control groups. The newly formed tissue was uniform in all samples, having a characteristic fibrous tissue-like appearance. Interestingly, the length of the repaired lesion was highest in the auricular based specimens, which also demonstrated a higher overall rate of repair: more than $65 \%$ of samples were repaired compared to more than $55 \%$ of the articular specimens. This histological finding is consistent with higher biomechanical testing values in fracture energy, stiffness and extension of the tested samples. These results may also be due to the fact that auricular chondrocytes produce a higher amount of elastin than articular chondrocytes. Regarding the issue of using allogeneic cells, they showed a slightly lower complete healing rate than the use of autologous cells. Although cellular rejection might be expected when using allogeneic cells, none of the menisci repaired with allogeneic articular or auricular cells had evidence of immune rejection. Only few histiocytes were observed within the newly formed tissue, and these may be related to a foreign body reaction to the Vicryl scaffold. Possible explanations for the absence of an inflammatory reaction include the avascular environment into which the implant is placed and questionable expression of MHC antigens on the surface of the chondrocytes (Bujia et al., 1994). In all, these studies suggested that allogeneic cell populations have a potential to repair tears in the meniscus, used in combination with biodegradable scaffolds, and that auricular chondrocytes could provide complete healing. Moreover, the use of allogeneic cells could overcome the potential clinical limitations of donor site morbidity and inadequate cell numbers, which represent the main bottleneck to the clinical application of every single cellbased strategy.

From a surgical point of view, a suture capable to release in a controlled manner trophic GF or a cellular gel acting as a biological glue could be more manageable tools than a solid matrix to improve the bonding obtained with meniscal sutures. The first approach has been investigated by Kopf et al. (2010), reporting the results of a VEGFcoated non-absorbable suture for meniscal repair in a sheep orthotopic model. Although very interesting, this approach did not improve meniscal healing, probably because of the 
inappropriate kinetics of VEGF release. In this regard, an ectopic nude mouse study was performed, consisting of the evaluation of the potential of bonding meniscal slices by cellular fibrin glue (Peretti et al., 2008; Scotti et al., 2009). In this study, the firm gross bonding seen macroscopically was confirmed by the histology, as the cellular fibrin glue provided a microscopic bonding between the two meniscal slices through a fibrocartilaginous tissue. Moreover, penetration buds from the cellular fibrin glue to the native meniscal tissue were evident. This represents a positive finding as we had previously demonstrated that this characteristic is associated with an improved bonding (Peretti et al., 1998; Peretti et al., 1999). Additionally, these features were not found in the control samples, confirming the need of cells to grant bonding between tissues. However, further in vivo studies in an orthotopic model are needed to evaluate the feasibility of this approach in a weight-bearing environment.

\section{Partial meniscus engineering}

From a clinical standpoint, partial meniscus regeneration represents a critical topic since the treatment of irreparable lesions of the avascular zone of the meniscus is still an open issue.

Following the large clinical experience with CMI, Martinek et al. (2006) reported an interesting study on an autologous fibrochondrocytes-loaded CMI implanted in an ovine orthotopic model with a short-term follow up (3 months). The implant was pre-cultured in vitro for 3 weeks to allow for cell adhesion and ECM deposition, and then implanted orthotopically. Cell-seeding was demonstrated to improve the mechanical properties and histological results. However, the tissue-engineered meniscus was biomechanically unstable and the implant size reduced during the three-month observation period. Therefore, the authors suggested that an improvement in scaffold and cell seeding procedure was required before human application.

SIS has been applied to menisci regeneration in an orthotopic dog model in a 12 months follow-up study (Cook et al., 2006). In this study, partially meniscectomised menisci receiving cell-free SIS in a posterior vascular lesion had more tissue filling in the defects, with a meniscus-like tissue, and significantly less cartilage damage than menisci receiving no implants. Authors concluded that SIS implantation had better results than meniscectomy. Despite these positive experimental findings, it has been demonstrated that SIS evokes a TH-2 lymphocytes mediated immune response (Ansaloni et al., 2007), probably dependent on the presence of porcine DNA. However, this response usually does not determine graft rejection and it is used in clinical practice in inguinal hernioplasty (Ansaloni et al., 2007).

MSC seeded onto a hyaluronan-collagen-based scaffold were recently used to repair a critical-size defect in an orthotopic rabbit model, with a tissue engineering approach (Angele et al., 2008). In this study, the authors removed the pars intermedia of the medial meniscus and replaced the resected section with the biocompatible scaffold only, or with the scaffold loaded with MSC and previously cultured in vitro for $14 \mathrm{~d}$. Menisci repaired with the cell-free scaffold showed only a fibrous, scar-like repair tissue, while those repaired with the engineered tissue demonstrated a significantly better filling and meniscal regeneration. However, the cell-loaded and precultured implants did not completely restore the surface area and the tissue quality of normal meniscus. The authors concluded that, even if further studies are needed to optimise this approach, MSC demonstrated a potential for the regeneration of meniscal defects (Angele et al., 2008). In a more recent orthotopic study, the same authors evaluated the regeneration potential of hyaluronan-collagen matrices without cells, loaded with platelet-rich plasma, autologous bone marrow, or autologous MSC in a $2 \mathrm{~mm}$ punch defect model (Zellner et al., 2010). This study presented several interesting findings. First, neither bone marrow nor platelet-rich plasma loaded onto the matrices determined an improved healing compared with cell-free implants. Second, the implantation of $14 \mathrm{~d}$ precultured MSC-matrix constructs in chondrogenic medium resulted only in fibrocartilage-like repair tissue, displaying incomplete integration with the host meniscus. Third, non-precultured MSC in hyaluronancollagen composite matrices stimulated the development of completely integrated meniscus-like repair tissue. The latter suggests the potential for an intra-operative, onestep approach for partial meniscus tissue engineering with autologous MSC and a proper biomaterial. However, the defect model used in this study does not reflect the typical meniscal lesion, and therefore the translation of this approach to clinical practice may require further studies.

\section{Total meniscus engineering}

Total meniscus tissue engineering may be considered as a potential alternative to allografts, in order to overcome by means of an autologous tissue the problems of availability, immune reaction and sizing related to allotransplantation. However, tissue engineering techniques have been applied to meniscal regeneration with controversial results, and only a few studies investigated in orthotopic models the feasibility of engineering total meniscus substitutes (Kon et al., 2008; Kang et al., 2006).

Kang et al. (2006) described a PGA-PLGA scaffold seeded with allogeneic meniscal cells in a rabbit total meniscectomy model. The authors reported positive results at 36 weeks, with a neotissue resembling the normal meniscus by histology. Both the overall histological appearance and mechanical properties improved over the experimental times. Importantly, the seeded scaffolds showed no shrinkage or shape alterations at 36 weeks, while the unseeded scaffold showed failure of maintenance of shape and size. Less severe cartilage degeneration was observed in the rabbits treated with the seeded scaffolds. No or minor immune response was observed. In conclusion, this study demonstrated the feasibility of total meniscus substitution with a tissue engineering approach using a polymer scaffold and allogeneic fibrochondrocytes, highlighting the role of seeded cells in maintaining shape and size and for chondroprotection.

A crucial aspect of scaffold design for meniscus tissue engineering was highlighted by Baker and Mauck (2007) reporting that nanofibres alignment served as a micro-pattern for directed tissue ingrowth and that, when cell-seeded with bovine meniscal cells or MSC, resulted 
in better tissue properties in a PCL meniscal scaffold. An important finding of this study was that the improvement in mechanical properties depended on the overall better organisation of the tissue and not on a higher neotissue deposition. Considering the fine organisation of the native meniscal collagen fibres, these results seem particularly relevant to meniscal scaffold design. In a more recent study by the same authors with human cells harvested by adult human donors, they reported better results with fibrochondrocytes compared to MSC (Baker et al., 2010). This concept has been further optimised, reaching near-native properties in tension, and showed multiscale collagen organisation in the scaffolds (Baker et al., 2012). A further fibre-reinforced degradable scaffold for meniscus tissue engineering was developed by Balint et al. (2012) with the hypothesis that the fibre network design shares part of the compressive loads via the generation of circumferential tensile loads, resulting in tensile properties similar to those of the meniscus.

Chiari et al. (2006) described the early results of a cell-free hyaluronan-PCL scaffold in an orthotopic large animal model. Their study was aimed to evaluate the biocompatibility, tissue ingrowth and neovascularisation properties of this material and demonstrated tissue formation and bonding to the capsule with an overall satisfactory integration in the host joint. Additionally, abundant blood vessels were found in the scaffold after 6 weeks. According to these favourable preliminary results, Kon et al. (2008) investigated the use of this biomaterial seeded with expanded autologous articular chondrocytes in the same orthotopic model in order to improve the biological response and the remodelling processes. At the end of the experimental time (16 weeks) no significant macroscopic difference was evident between the cellseeded and the cell-free implant. However, histological analysis demonstrated deposition of cartilaginous matrix only in the cell-seeded scaffold. Moreover, the authors reported that the cartilaginous distribution was mainly located at the edges and the tip of the implants, consistent with the distribution of cells at the time of grafting, thus confirming that matrix deposition depended on or at least was enhanced by the previously seeded cells. Additionally, the implants were well tolerated immunologically, with only a mild foreign body giant-cell reaction. Limited peripheral implant extrusion was frequently observed. The authors concluded that the hyaluronan-PCL scaffold had a potential for total meniscus regeneration and that the seeding of the scaffold provided some benefits at 4 months follow-up allowing for a larger amount of fibrocartilaginous tissue formation. A following study with 12-month evaluation confirmed the improvement in tissue formation within the tissue engineered menisci, but showed no significant differences in protection from osteoarthritic degeneration between cell-seeded and cell-free scaffolds (Kon et al., 2012). However, both cell-seeded and cell-free implants resulted in better chondroprotection compared to meniscectomised knees.

The results of an orthotopic study in dogs with a 6-month and 2-year follow up have been reported (Welsing et al., 2008; Hannink et al., 2011). In this study, they compared the outcome of total meniscectomy with that of the implant of a PU-PCL total meniscal implant. This work followed a large series of in vitro and in vivo experimental studies on the development of this scaffold (Heijkants et al., 2005; Heijkants et al., 2004; van Tienen et al., 2009). The authors described satisfactory integration and fibrovascular tissue ingrowth into the implant with mild foreign body reaction. However, specific structural organisation and a fibrocartilage phenotype was lacking after both 6 and 24 months. The porous polymer scaffold was histologically not noticeably degraded after 24 months, thus confirming the expected slow degradation rate of this implant. Surprisingly, chondroprotection was not superior compared to that of knees that underwent meniscectomy only. The authors concluded that further improvements in the implant model and surgical technique were needed for making the implant suitable for clinical application in totally meniscectomised patients. In fact, the clinical scenario in which a PU-PCL cell-free scaffold is currently used (Actifit ${ }^{\mathrm{TM}}$, Orteq Ltd, London, UK) is represented by irreparable meniscal tears or partial meniscal defects. In addition, in vitro studies are currently being performed to evaluate the feasibility of a cell-based approach using this scaffold (de Mulder et al., 2013). In particular, addition of TGF- $\beta$ seems to be mandatory in order to promote MC proliferation and distribution throughout the construct (de Mulder et al., 2013).

Kobayashi and co-workers described a cell-free total meniscus replacement model based on high water content PVA hydrogel in a rabbit model (Kobayashi et al., 2003; Kobayashi et al., 2005). Authors reported successful results in terms of chondroprotection. In particular, they proposed this strategy as salvage procedure for young athletes since it could allow for early return to athletic activity. However, some concerns have been raised regarding implant longterm durability, safety and also on the fixation method. Another interesting cell-free hydrogel approach has been reported by Kelly et al. (2007), consisting of the use of a hydrogel-based implant that was secured and reinforced by sutures running circumferentially through it. However, significant cartilage degeneration and implant failure were seen at 1 year, and overall performance was worse than with allograft transplantation. The authors hypothesised that the source of graft failure arose from the size mismatch, the inadequate peripheral fixation of the hydrogel implant, or the structural composition of these particular implants.

Mandal et al. (2011a) described the development of a tissue engineered meniscus based on a tri-layered silk fibrous protein scaffold and human expanded fibroblasts, seeded in the outer part, and human expanded chondrocytes, seeded in the inner part. According to the authors, its versatile processability, outstanding mechanical properties and biocompatibility make silk fibrous protein an ideal biopolymer for meniscus regeneration purposes. The rationale of using a tri-layered scaffold was to duplicate the native meniscus pores architecture. Fibroblasts and chondrocytes were seeded in each scaffold layer separately and cultured for $28 \mathrm{~d}$. The resulting tissues displayed biochemical and biomechanical properties consistent with those of the native human meniscus. In a second study, the same authors reported the use of human MSC in such tri-layered scaffold showing native-like 
compressive properties and tissue structure (Mandal et al., 2011b). However, the three layers should be combined firmly before an in vivo application is planned: the authors hypothesised that cell-deposited ECM and cell migration, eventually supplemented with stitches or a rivet approach (e.g., using silk cylindrical pieces pushed into holes through the layers) can help to keep together the three layers.

An interesting and clinically-relevant approach is represented by image-guided tissue engineering of critically-sized whole meniscus constructs. In particular, because of its complex geometry, meniscus engineering can benefit from computer-aided design and tissue injection moulding techniques. Ballyns et al. (2008) demonstrated the feasibility of this approach by engineering a critically sized meniscus with bovine and ovine fibrochondrocytes suspended in agarose hydrogel. Even if the cells were not of human origin, this is an important proof of principle, opening new possibilities in meniscus tissue engineering.

A further innovative strategy is represented by the development of a self-assembled, scaffold-free engineered meniscal tissue (Aufderheide and Athanasiou, 2007). According to this strategy, high-density co-cultures of MSC and fibrochondrocytes have been performed in ring-shaped moulds. This approach maximises cell-to-cell contact and interaction between differentiated fibrochondrocytes and undifferentiated MSC. An interesting finding of this study was that the tensile modulus was proportional to the percentage of fibrochondrocytes employed. However, a $50 \%$ ratio of cells displayed overall better results. Scaffold-free constructs were also compared to cell-loaded PGA scaffold and were stiffer and stronger in tension with circumferential fibres similar to those of native tissue. On the other hand, cell-loaded PGA scaffold did not present a defined fibre direction. The authors suggested that the geometric constraint imposed by the ring-shaped, non-adhesive mould guided collagen fibril directionality and, thus, influenced mechanical properties. In another work, authors showed that the mechanical properties of a scaffoldless, self-assembled meniscus tissue, obtained by culturing bovine articular chondrocytes and meniscal cells in elliptical agarose wells, can be improved by addition of TGF- $\beta 1$ and chondroitinase-ABC (Huey and Athanasiou, 2011). In particular, in this study 20 million cells were used to engineer a rabbit-sized meniscus tissue. Although this method is very promising, the large number of cells needed represents a limitation to the clinical application of this approach, which, anyway, does not exclude the use of a biomaterial as augmentation to reach a clinically-relevant size with a reasonable number of cells (Makris et al., 2011).

Although promising, results of recent experimental studies prompt for new strategies for total meniscus engineering as mere cell seeding does not result typically in an improved outcome and chondroprotection (Kon et al., 2012). In addition, the ideal biomaterial for meniscus tissue engineering has still to be developed. For these reasons, alternative and more effective methods are desirable. In this regard, a critical tool to develop more functional engineered tissues, possibly leading to improved outcomes, is represented by bioreactors.

\section{Bioreactors for meniscus engineering}

Engineering of critically sized cellular grafts using standard static culture conditions is typically challenged by inefficient mass transport to the internal regions of the construct, ultimately resulting in cell death and necrosis in the tissue core (Martin et al., 2004). A possible solution to this issue is offered by bioreactor-based dynamic culture techniques, allowing for medium perfusion through the pores of the scaffold or convective media flow around the construct, thus overcoming diffusional transport limitations (Wendt et al., 2009). In the context of meniscus engineering, it was reported that hydrodynamic forces generated by a spinning impeller could result in the formation of bizonal tissues, resembling the structure and function of native meniscus (Marsano et al., 2006). In this study, medium mixing around the constructs imparted orientation of the extracellular matrix molecules in an outer zone and at the same time an enhanced mass transport in the inner zone. This resulted in the formation of circumferential collagen fibres in the peripheral region, associated with higher stiffness in tension, and in increased amounts of GAGs in the central region, associated with higher stiffness in compression. The range of effective mixing intensities, generated by different impeller speeds and quantified by the corresponding Reynolds numbers, was further investigated using anatomically shaped engineered constructs (Ballyns et al., 2010). The findings indicated that fluid mixing can be optimised to modulate the spatial heterogeneity of engineered menisci, as well as the correlated mechanical properties.

Compressive deformation or hydrostatic pressure have alternatively been used to enhance the structure and function of engineered meniscus tissues. Dynamic compression of constructs based on micro-channelled scaffolds resulted in aligned cell layers and collagen fibres (Martinez et al., 2012), while hydrostatic pressure combined with TGF- $\beta 1$ increased collagen and GAG deposition by meniscus cells, ultimately leading to enhanced compressive properties (Gunja and Athanasiou, 2010). Cyclic tension specifically stimulated collagen I mRNA expression and protein synthesis, but had no effect on collagen II, aggrecan, or osteocalcin mRNA levels resulting in enhanced fibrochondrocyte-like differentiation of bone marrow-derived MSC (Connelly et al., 2010). Combinatorial modes of mechanical stimulation, including tension-compression loading (Huey and Athanasiou, 2011) or perfusion and cyclic compression (Petri et al., 2012), were also reported to additively increase matrix production and tissue mechanical properties.

The availability of dynamic culture systems allowing generation of tissue grafts with superior mechanical properties raises the question of "how good is good enough?", and thus what is the target level of functionality which is required to support a superior clinical outcome. Indeed, an increased level of maturation of engineered meniscus grafts would require not only more complex culture modalities, but also likely longer culture durations, which in view of a clinical translation would be reflected in higher manufacturing costs. Addressing this critical issue requires one to identify a match between the properties of 
a meniscus graft and a suitable regime of post-operative rehabilitation. In this regard, the use of bioreactors applying regimes of forces mimicking those at the site of implantation offers the opportunity to investigate which structural and functional properties are sufficient to tolerate certain loading regimes that would be experienced by the graft upon implantation, or vice versa which loading regimes are compatible for grafts of a defined functionality (Dèmarteau et al., 2003).

The introduction of bioreactor systems in the manufacturing of cellular grafts can not only be exploited to reach higher levels of tissue organisation and mechanical functionality, but also to reduce operator handling, automate processes and ultimately standardise the quality of the product (Martin et al., 2009). A bioreactor-based manufacturing would thus be critical to make tissue engineered products available at an industrial scale and quality, similar to what has been achieved in other better established biotechnological sectors (e.g., for production of antibodies, vaccines, and recombinant proteins).

Finally, the use of state-of-the-art monitoring and control systems for relevant culture parameters, which is a standard feature of classical 'fermenters', would introduce the important advantage of a well-defined environment in the engineering of meniscus tissues. The availability of controlled culture conditions is crucial to test the effect of specific factors on the development of a meniscus tissue and would thus support a better understanding of regenerative processes at a cellular and molecular level (Rouwkema et al., 2011). Ultimately, this knowledge will be critical to identify factors that may induce in vivo regeneration and thus instrumental to operate the expected transition from the classical tissue-engineering approaches to the more modern concepts of regenerative medicine, relying on our body as the "in vivo bioreactor" for in situ tissue production.

\section{Conclusion}

Meniscus tissue is a crucial player in knee homeostasis. Re-establishing its integrity after injury is now considered a mandatory approach in knee surgery. However, current procedures result in variable outcomes while experimental strategies hold great potential to address this relevant clinical challenge. Cell-based biological bonding studies showed the possibility to improve the healing of meniscus tears treated with sutures, which would normally heal only in the red-red zone. However, the lack of efficient intra-operative systems for the isolation of autologous cells impedes its clinical application. Tissue engineering strategies showed several biological implants trying to address the regeneration of a part or the whole meniscus tissue when meniscectomy has to be performed. None of these cell-based strategies has entered clinical practice to date, since results on large animal studies have been controversial with no clear benefits. Functional engineered tissue has not been demonstrated to date upon orthotopic implantation. In fact, the relevance of engineered tissue generated ectopically (e.g., in subcutaneous pouches of nude mice) is limited and more pre-clinical evidence in large animals orthotopic models is desirable. In addition, the ideal biomaterial characterised by appropriate mechanical properties and providing adequate environment to cells for tissue regeneration has still to be described. However, new technologies and advancements in molecular biology, genetics and bioengineering research have the potential to foster meniscus research towards the solution of this clinical challenge.

\section{Acknowledgments}

The authors thank Dr. Alessia Di Giancamillo for the expert help in preparing Fig. 1 and Dr. Rosa Ballis for drawing Fig. 2. We wish to confirm that there are no known conflicts of interest associated with this publication and there has been no significant financial support for this work that could have influenced its outcome.

\section{References}

Adams ME, Hukins DWL (1992) The extracellular matrix of the meniscus. In: Mow VC, Arnoczky SP, Jackson DW (eds) Knee Meniscus: Basic and Clinical Foundations. Raven Press, New York, pp 15-28.

Ahmed AM, Burke DL (1983) In vitro measurement of static pressure distribution in synovial joints: Part I. Tibial surface of the knee. J Biomech Eng 105: 216-225.

Allen PR, Denham RA, Swan AV (1984) Late degenerative changes after meniscectomy: factors affecting the knee after operation. J Bone Joint Surg 66B: 666-671.

Anderson DE, Athanasiou KA (2009) A comparison of primary and passaged chondrocytes for use in engineering the temporomandibular joint. Arch Oral Biol 54: 138-145.

Angele P, Johnstone B, Kujat R, Zellner J, Nerlich M, Goldberg V, Yoo J (2008) Stem cell based tissue engineering for meniscus repair. J Biomed Mater Res A 85: 445-455.

Ansaloni L, Cambrini P, Catena F, Di Saverio S, Gagliardi S, Gazzotti F, Hodde JP, Metzger DW, D'Alessandro L, Pinna AD (2007) Immune response to small intestinal submucosa (surgisis) implant in humans: preliminary observations. J Invest Surg 20: 237-241.

Appel H (1970) Late results after meniscectomy in the knee joint: a clinical and roentgenologic follow up investigation. Acta Orthop Scand 133 (Suppl): 1-111.

Arnoczky SP (1999) Building a meniscus. Biologic considerations. Clin Orthop Relat Res 367 Suppl: S244253.

Arnoczky SP, Warren RF (1982) Microvasculature of the human meniscus. Am J Sports Med 10: 90-95.

Arnoczky SP, Warren RF (1983) The microvasculature of the meniscus and its response to injury: an experimental study in the dog. Am J Sports Med 11: 131-141.

Arnoczky SP, Adams ME, DeHaven K, Eyre DR, Mow VC (1988) The meniscus. In: Woo SL-Y, Buckwalter J. (eds) Injury and Repair of the Musculoskeletal Soft Tissues. American Academy of Orthopaedic Surgeons, Park Ridge, pp 487-537.

Arnold MP, Hirschmann MT, Verdonk PC (2012) See the whole picture: knee preserving therapy needs more 
than surface repair. Knee Surg Sports Traumatol Arthrosc 20: 195-196.

Aufderheide AC, Athanasiou KA (2007) Assessment of a bovine co-culture, scaffold-free method for growing meniscus-shaped constructs. Tissue Eng 13: 2195-2205.

Baker BM, Mauck RL (2007) The effect of nanofiber alignment on the maturation of engineered meniscus constructs. Biomaterials 28: 1967-1977.

Baker BM, Nathan AS, Huffman GR, Mauck RL (2009) Tissue engineering with meniscus cells derived from surgical debris. Osteoarthritis Cartilage 17: 336-345.

Baker BM, Nathan AS, Gee AO, Mauck RL (2010) The influence of an aligned nanofibrous topography on human mesenchymal stem cell fibrochondrogenesis. Biomaterials 31: 6190-6200.

Baker BM, Shah RP, Silverstein AM, Esterhai JL, Burdick JA, Mauck RL (2012) Sacrificial nanofibrous composites provide instruction without impediment and enable functional tissue formation. Proc Natl Acad Sci USA 109: 14176-14181.

Balint E, Gatt CJ Jr, Dunn MG (2012) Design and mechanical evaluation of a novel fiber-reinforced scaffold for meniscus replacement. J Biomed Mater Res A 100: 195-202.

Ballyns JJ, Gleghorn JP, Niebrzydowski V, Rawlinson JJ, Potter HG, Maher SA, Wright TM, Bonassar LJ (2008) Image-guided tissue engineering of anatomically shaped implants via MRI and micro-CT using injection molding. Tissue Eng Part A 14: 1195-1202.

Ballyns JJ, Wright TM, Bonassar LJ (2010) Effect of media mixing on ECM assembly and mechanical properties of anatomically-shaped tissue engineered meniscus. Biomaterials 31: 6756-6763.

Barber FA (1994) Accelerated rehabilitation for meniscus repairs. Arthroscopy 10: 206-210.

Berjon JJ, Munuera L, Calvo M (1991) Degenerative lesions in the articular cartilage after meniscectomy: preliminary experimental study in dogs. J Trauma 31: 342-350.

Bhargava MM, Attia ET, Murrell GA, Dolan MM, Warren RF, Hannafin JA (1999) The effect of cytokines on the proliferation and migration of bovine meniscal cells. Am J Sports Med 27: 636-643.

Bland Sutton J (1987) The ligaments of the knee joint. In: Bland Sutton J (ed) Ligaments, Their Nature and Morphology, 2nd ed. HK Lewis, London, pp 32-38.

Bodin A, Concaro S, Brittberg M, Gatenholm P (2007) Bacterial cellulose as a potential meniscus implant. J Tissue Eng Regen Med 1: 406-408.

Bruns J, Kahrs J, Kampen J, Behrens P, Plitz W (1998) Autologous perichondral tissue for meniscal replacement. J Bone Joint Surg Br 80: 918-923.

Bujia J, Alsalameh S, Sittinger M, Hammer C, Wilmes E, Burmester G (1994) Antigen-presenting cell-function of class-II positive human nasal chondrocytes. Acta Otolaryngol 114: 75-79.

Bulgheroni P, Murena L, Ratti C, Bulgheroni E, Ronga M, Cherubino P (2010) Follow-up of collagen meniscus implant patients: clinical, radiological, and magnetic resonance imaging results at 5 years. Knee 17: 224-229.
Buma P, Ramrattan NN, van Tienen TG, Veth RP (2004) Tissue engineering of the meniscus. Biomaterials 25: $1523-1532$.

Candrian C, Vonwil D, Barbero A, Bonacina E, Miot S, Farhadi J, Wirz D, Dickinson S, Hollander A, Jakob M, Li Z, Alini M, Heberer M, Martin I (2008) Engineered cartilage generated by nasal chondrocytes is responsive to physical forces resembling joint loading. Arthritis Rheum 58: 197-208.

Cao Y, Rodriguez A, Vacanti M, Ibarra C, Arevalo C and Vacanti CA (1998) Comparative study of the use of poly(glycolic acid), calcium alginate and pluronics in the engineering of autologous porcine cartilage. J Biomater Sci Polym Ed 9: 475-487.

Caplan AI (1991) Mesenchymal stem cells. J Orthop Res 9: 641-650.

Caplan AI (2007) Adult mesenchymal stem cells for tissue engineering versus regenerative medicine. J Cell Physiol 213: 341-347.

Caplan AI, Correa D (2011) The MSC: an injury drugstore. Cell Stem Cell 9:11-15.

Chevrier A, Nelea M, Hurtig MB, Hoemann CD, Buschmann MD (2009) Meniscus structure in human, sheep, and rabbit for animal models of meniscus repair. $\mathrm{J}$ Orthop Res 27:1197-1203.

Chiari C, Koller U, Dorotka R, Eder C, Plasenzotti R, Lang S, Ambrosio L, Tognana E, Kon E, Salter D, Nehrer $S$ (2006) A tissue engineering approach to meniscus regeneration in a sheep model. Osteoarthritis Cartilage 14: 1056-1065.

Clark CR, Ogden JA (1983) Development of the menisci of the human knee joint. Morphological changes and their potential role in childhood meniscal injury. J Bone Jt Surg Am 65:538-547.

Cole BJ, Carter TR, Rodeo SA (2003) Allograft meniscal transplantation: background, techniques, and results. Instr Course Lect 52: 383-396.

Collier S, Ghosh P (1995) Effects of transforming growth factor beta on proteoglycan synthesis by cell and explant cultures derived from the knee joint meniscus. Osteoarthritis Cartilage 3: 127-138.

Connelly JT, Vanderploeg EJ, Mouw JK, Wilson CG, Levenston M (2010) Tensile loading modulates bone marrow stromal cell differentiation and the development of engineered fibrocartilage constructs. Tissue Eng Part A 16:1913-1923.

Cook JL, Tomlinson JL, Kreeger JM, Cook CR (1999) Induction of meniscal regeneration in dogs using a novel biomaterial. Am J Sports Med 27: 658-665.

Cook JL, Fox DB, Malaviya P, Tomlinson JL, Kuroki K, Cook CR, Kladakis S (2006) Long-term outcome for large meniscal defects treated with small intestinal submucosa in a dog model. Am J Sports Med 34: 32-42.

Cooper DE, Arnoczky SP, Warren RF (1990) Arthoscopic meniscal repair. Clin Sports Med 9: 589-607.

Cooper DE, Arnoczky SP, Warren RF (1991) Meniscal repair. Clin Sports Med 9: 529-548.

Cucchiarini M, Schetting S, Terwilliger EF, Kohn D, Madry H (2009) rAAV-mediated overexpression of FGF2 promotes cell proliferation, survival, and alpha-SMA 
expression in human meniscal lesions. Gene Ther 16:13631372.

Daniel R, Smith JA (2008) Integration site selection by retroviral vectors: molecular mechanism and clinical consequences. Hum Gene Ther 19: 557-568.

De Bari C, Dell'Accio F, Luyten FP (2001a) Human periosteum-derived cells maintain phenotypic stability and chondrogenic potential throughout expansion regardless of donor age. Arthritis Rheum 44: 85-95.

De Bari C, Dell'Accio F, Tylzanowski P, Luyten FP (2001b) Multipotent mesenchymal stem cells from adult human synovial membrane. Arthritis Rheum 44: 19281942.

De Bari C, Dell'Accio F, Luyten FP (2004) Failure of in vitro-differentiated mesenchymal stem cells from the synovial membrane to form ectopic stable cartilage in vivo. Arthritis Rheum 50: 142-150.

De Bari C, Pitzalis C, Dell'Accio F (2007) Joint tissue engineering. In: Habib NA, Levicar N, Gordon MY, Jiao L, Fisk N (eds) Stem Cell Repair and Regeneration, vol 2. Imperial College Press, London, pp107-123.

de Mulder EL, Hannink G, Giele M, Verdonschot N, Buma P (2013) Proliferation of meniscal fibrochondrocytes cultured on a new polyurethane scaffold is stimulated by TGF- $\beta$. J Biomater Appl 27: 617-626.

DeHaven KE (1985) Rationale for meniscus repair or excision. Clin Sports Med 4: 267-273.

DeHaven KE (1990) Decision-making factors in the treatment of meniscus lesions. Clin Orthop Relat Res 252: 49-54.

Démarteau O, Wendt D, Braccini A, Jakob M, Schäfer D, Heberer M, Martin I (2003) Dynamic compression of cartilage constructs engineered from expanded human articular chondrocytes. Biochem Biophys Res Commun 310: $580-588$.

Deponti D, Giancamillo AD, Scotti C, Peretti GM, Martin I (2013) Animal models for meniscus repair and regeneration. J Tissue Eng Regen Med doi:10.1002/ term. 1760 .

Dye SF (1996) The knee as a biologic transmission with an envelope of function: a theory. Clin Orthop Relat Res 325: 10-18.

Efe T, Getgood A, Schofer MD, Fuchs-Winkelmann S, Mann D, Paletta JR, Heyse TJ (2012) The safety and shortterm efficacy of a novel polyurethane meniscal scaffold for the treatment of segmental medial meniscus deficiency. Knee Surg Sports Traumatol Arthrosc 20: 1822-1830.

Elattar M, Dhollander A, Verdonk R, Almqvist KF, Verdonk P (2011) Twenty-six years of meniscal allograft transplantation: is it still experimental? A meta-analysis of 44 trials. Knee Surg Sports Traumatol Arthrosc 19: 147157.

Evans CH, Robbins PD. (1999) Genetically augmented tissue engineering of the musculoskeletal system. Clin Orthop Relat Res 367 (Suppl): S410-418.

Fairbank TJ (1948) Knee joint changes after meniscectomy. J Bone Joint Surg Br 30B: 664-670.

Freed LE, Marquis JC, Nohria A, Emmanual J, Mikos AG, Langer R (1993) Neocartilage formation in vitro and in vivo using cells cultured on synthetic biodegradable polymers. J Biomed Mater Res 27: 11-23.
Ghosh P, Taylor TKF (1987) The knee joint meniscus. A fibrocartilage of some distinction. Clin Orthop 224: 52-63.

Ghosh P, Sutherland J, Bellenger C, Read R, Darvodelsky A (1990) The influence of weight-bearing exercise on articular cartilage of meniscectomized joints: an experimental study in sheep. Clin Orthop 252: 101-113.

Goto H, Shuler FD, Lamsam C, Moller HD, Niyibizi C, Fu FH, Robbins PD, Evans CH. (1999) Transfer of lacZ marker gene to the meniscus. J Bone Joint Surg Am 81: 918-925.

Goto H, Shuler FD, Niyibizi C, Fu FH, Robbins PD, Evans CH (2000) Gene therapy for meniscal injury: enhanced synthesis of proteoglycan and collagen by meniscal cells transduced with a TGFbeta(1)gene. Osteoarthritis Cartilage 8: 266-271.

Gunja NJ, Athanasiou KA (2010) Effects of hydrostatic pressure on leporine meniscus cell-seeded PLLA scaffolds. J Biomed Mater Res A 92: 896-905.

Han SB, Shetty GM, Lee DH, Chae DJ, Seo SS, Wang KH, Yoo SH, Nha KW (2010) Unfavorable results of partial meniscectomy for complete posterior medial meniscus root tear with early osteoarthritis: a 5- to 8-year follow-up study. Arthroscopy 26: 1326-1332.

Hannink G, van Tienen TG, Schouten AJ, Buma P (2011) Changes in articular cartilage after meniscectomy and meniscus replacement using a biodegradable porous polymer implant. Knee Surg Sports Traumatol Arthrosc 19:441-451.

Harston A, Nyland J, Brand E, McGinnis M, Caborn DN (2012) Collagen meniscus implantation: a systematic review including rehabilitation and return to sports activity. Knee Surg Sports Traumatol Arthrosc 20: 135-146.

Heijkants RG, van Calck RV, De Groot JH, Pennings AJ, Schouten AJ, van Tienen TG, Ramrattan N, Buma P, Veth RP (2004) Design, synthesis and properties of a degradable polyurethane scaffold for meniscus regeneration. J Mater Sci Mater Med 15:423-427.

Heijkants RG, van Calck RV, van Tienen TG, de Groot JH, Buma P, Pennings AJ, Veth RP, Schouten AJ (2005) Uncatalyzed synthesis, thermal and mechanical properties of polyurethanes based on poly(epsilon-caprolactone) and 1,4-butane diisocyanate with uniform hard segment. Biomaterials 26: 4219-4228.

Herzog EL, Chai L, Krause DS (2003) Plasticity of marrow-derived stem cells. Blood 102: 3483-3493.

Hidaka C, Ibarra C, Hannafin JA, Torzilli PA, Quitoriano M, Jen SS, Warren RF, Crystal RG (2002) Formation of vascularized meniscal tissue by combining gene therapy with tissue engineering. Tissue Eng 8: 93-105.

Hirschmann MT, Friederich NF (2009) Meniscal lesions in children: classifications. In: Beaufils P, Verdonk R (eds) The Meniscus. Springer-Verlag, Berlin Heidelberg, pp 241-246.

Hoben GM, Athanasiou KA (2008) Creating a spectrum of fibrocartilages through different cell sources and biochemical stimuli. Biotechnol Bioeng 100: 587-598.

Hoben GM, Koay EJ, Athanasiou KA (2008) Fibrochondrogenesis in two embryonic stem cell lines: effects of differentiation timelines. Stem Cells 26: 422-430. 
Hoch DH, Grodzinsky AJ, Koob TJ, Albert ML, Eyre DR (1983) Early changes in material properties of rabbit articular cartilage after meniscectomy. J Orthop Res 1: 4-12.

Hoffelner T, Resch H, Forstner R, Michael M, Minnich B, Tauber M (2011) Arthroscopic all-inside meniscal repair - Does the meniscus heal? A clinical and radiological follow-up examination to verify meniscal healing using a 3-T MRI. Skeletal Radiol 40: 181-187.

Hommen JP, Applegate GR, Del Pizzo W (2007) Meniscus allograft transplantation: ten-year results of cryopreserved allografts. Arthroscopy 23: 388-393.

Horie M, Sekiya I, Muneta T, Ichinose S, Matsumoto K, Saito H, Murakami T, Kobayashi E (2009) Intra-articular Injected synovial stem cells differentiate into meniscal cells directly and promote meniscal regeneration without mobilization to distant organs in rat massive meniscal defect. Stem Cells 27: 878-887.

Huckell JR (1965) Is meniscectomy a benign procedure? A long term follow up study. Can J Surg 8: 254-260.

Huey DJ, Athanasiou KA (2011) Maturational growth of self-assembled, functional menisci as a result of TGF- $\beta 1$ and enzymatic chondroitinase-ABC stimulation. Biomaterials 32: 2052-2058.

Hyde G, Boot-Handford RP, Wallis GA (2008) Col2a1 lineage tracing reveals that the meniscus of the knee joint has a complex cellular origin. J Anat 213: 531-538.

Jackson JP (1968) Degenerative changes in the knee after meniscectomy. Br Med J 2: 525-527.

Jackson DW, Rosen M, Simon TM (1992) Soft tissue allograft reconstruction: the knee. In: Czitrom AA, Gross AE (eds) Allografts in Orthopaedic Practice. Williams \& Wilkins, Baltimore, pp 197-216.

Jackson DW, Whelan J, Simon TM (1993) Cell survival after transplantation of fresh meniscal allografts. DNA probe analysis in a goat model. Am J Sports Med 21: 540 550 .

Jacobi M, Jakob RP (2009) Meniscal repair: enhancement of healing process. In: Beaufils P, Verdonk R (eds) The Meniscus. Springer-Verlag, Berlin Heidelberg, pp 129-136.

Jiang D, Zhao LH, Tian M, Zhang JY, Yu JK (2012) Meniscus transplantation using treated xenogeneic meniscal tissue: viability and chondroprotection study in rabbits. Arthroscopy 28: 1147-1159.

Johns DE, Athanasiou KA (2008) Growth factor effects on costal chondrocytes for tissue engineering fibrocartilage. Cell Tissue Res 333: 439-447.

Johnson DL, Bealle D (1999) Meniscal allograft transplantation. Clin Sports Med 18: 93-108.

Johnson TS, Xu JW, Zaporojan VV, Mesa JM, Weinand C, Randolph MA, Bonassar LJ, Winograd JM, Yaremchuk MJ (2004) Integrative repair of cartilage with articular and nonarticular chondrocytes. Tissue Eng 10: 1308-1315.

Kang SW, Son SM, Lee JS, Lee ES, Lee KY, Park SG, Park JH, Kim BS (2006) Regeneration of whole meniscus using meniscal cells and polymer scaffolds in a rabbit total meniscectomy model. J Biomed Mater Res A 78: 659-671.

Katabi M, Pujol N, Boisrenoult P (2009) Meniscal repair: intra- and postoperative complications. In : Beaufils
P, Verdonk R (eds) The Meniscus. Springer-Verlag, Berlin Heidelberg, pp 191-198.

Kelly BT, Robertson W, Potter HG, Deng XH, Turner AS, Lyman S, Warren RF, Rodeo SA (2007) Hydrogel meniscal replacement in the sheep knee: preliminary evaluation of chondroprotective effects. Am J Sports Med 35: $43-52$.

Kim JM, Lee BS, Kim KH, Kim KA, Bin SI (2012) Results of meniscus allograft transplantation using bone fixation: 110 cases with objective evaluation. Am J Sports Med 40: 1027-1034.

King D (1936) The function of semilunar cartilages. J Bone Joint Surg 18: 1069-1076.

Klompmaker J, Jansen HW, Veth RP, Nielsen HK, de Groot JH, Pennings AJ (1993) Porous implants for knee joint meniscus reconstruction: a preliminary study on the role of pore sizes in ingrowth and differentiation of fibrocartilage. Clin Mater 14: 1-11.

Koay EJ, Athanasiou KA (2009) Development of serum-free, chemically defined conditions for human embryonic stem cell-derived fibrochondrogenesis. Tissue Eng Part A 15: 2249-2257.

Kobayashi M, Toguchida J, Oka M (2003) Preliminary study of polyvinyl alcohol-hydrogel (PVA-H) artificial meniscus. Biomaterials 24: 639-647.

Kobayashi M, Chang YS, Oka M (2005) A two year in vivo study of polyvinyl alcohol-hydrogel (PVA-H) artificial meniscus. Biomaterials 26: 3243-3248.

Kon E, Chiari C, Marcacci M, Delcogliano M, Salter DM, Martin I, Ambrosio L, Fini M, Tschon M, Tognana E, Plasenzotti R, Nehrer S (2008) Tissue engineering for total meniscal substitution: animal study in sheep model. Tissue Eng Part A 14: 1067-1080.

Kon E, Filardo G, Tschon M, Fini M, Giavaresi G, Marchesini Reggiani L, Chiari C, Nehrer S, Martin I Phd, Salter D, Ambrosio L, Marcacci M (2012) Tissue engineering for total meniscal substitution. Animal study in sheep model: results at 12 months. Tissue Eng Part A 18: $1573-1582$.

Krause WR, Pope HM, Johnson RJ, Wilder DG (1976) Mechanical changes in the knee after meniscectomy. J Bone Joint Surg 58A: 599-604.

Lebourg M, Sabater Serra R, Más Estellés J, Hernández Sánchez F, Gómez Ribelles JL, Suay Antón J (2008) Biodegradable polycaprolactone scaffold with controlled porosity obtained by modified particle-leaching technique. J Mater Sci Mater Med 19: 2047-2053.

Lee YH, Caborn DN (2012) A new technique for arthroscopic meniscus transplant using soft tissue fixation and anatomical meniscal root reinsertion. Knee Surg Sports Traumatol Arthrosc 20: 904-908.

Levy IM, Torzilli PA, Gould JUD, Warren RF (1989) The effect of lateral meniscectomy on motion of the knee. J Bone Joint Surg 71A: 401-406.

Lietman SA, Hobbs W, Inoue N, Reddi AH (2003) Effects of selected growth factors on porcine meniscus in chemically defined medium. Orthopedics 26: 799-803.

Longo UG, Campi S, Romeo G, Spiezia F, Maffulli N, Denaro V (2012) Biological strategies to enhance healing of the avascular area of the meniscus. Stem Cells Int 2012: 528359 . 
Lubowitz JH, Verdonk PC, Reid JB 3rd, Verdonk R (2007) Meniscus allograft transplantation: a current concepts review. Knee Surg Sports Traumatol Arthrosc 15: 476-492.

Lufti AM (1975) Morphological changes in the articular cartilage after meniscectomy. An experimental study in the monkey. J Bone Joint Surg 57B: 525-528.

Madry H, Cucchiarini M, Terwilliger EF, Trippel SB (2003) Recombinant adeno-associated virus vectors efficiently and persistently transduce chondrocytes in normal and osteoarthritic human articular cartilage. Hum Gene Ther 14: 393-402.

Madry H, Cucchiarini M, Kaul G, Kohn D, Terwilliger EF, Trippel SB (2004) Menisci are efficiently transduced by recombinant adeno-associated virus vectors in vitro and in vivo. Am J Sports Med 32: 1860-1865.

Majewski M, Stoll R, Müller W, Friederich NE (2009) Rotatory stability of the knee after arthroscopic meniscus suture repair: a 5-to-17-year follow-up study of isolated medial and lateral meniscus tears. Acta Orthop Belg 75: 354-359.

Makris EA, Hadidi P, Athanasiou KA (2011) The knee meniscus: structure-function, pathophysiology, current repair techniques, and prospects for regeneration. Biomaterials 32: 7411-7431.

Mandal BB, Park SH, Gil ES, Kaplan DL (2011a) Multilayered silk scaffolds for meniscus tissue engineering. Biomaterials 32: 639-651.

Mandal BB, Park SH, Gil ES, Kaplan DL (2011b) Stem cell-based meniscus tissue engineering. Tissue Eng Part A 17: 2749-2761.

Marsano A, Wendt D, Raiteri R, Gottardi R, Stolz M, Wirz D, Daniels AU, Salter D, Jakob M, Quinn TM, Martin I (2006) Use of hydrodynamic forces to engineer cartilaginous tissues resembling the non-uniform structure and function of meniscus. Biomaterials 27: 5927-5934.

Marsano A, Millward-Sadler SJ, Salter DM, Adesida A, Hardingham T, Tognana E, Kon E, Chiari-Grisar C, Nehrer S, Jakob M, Martin I (2007) Differential cartilaginous tissue formation by human synovial membrane, fat pad, meniscus cells and articular chondrocytes. Osteoarthritis Cartilage 15: 48-58.

Martin I, Wendt D, Heberer M (2004) The role of bioreactors in tissue engineering. Trends Biotechnol 22: 80-86.

Martin I, Smith T, Wendt D (2009) Bioreactor-based roadmap for the translation of tissue engineering strategies into clinical products. Trends Biotechnol 27: 495-502.

Martinek V, Usas A, Pelinkovic D, Robbins P, Fu FH, Huard J (2002) Genetic engineering of meniscal allografts. Tissue Eng 8: 107-117.

Martinek V, Ueblacker P, Bräun K, Nitschke S, Mannhardt R, Specht K, Gansbacher B, Imhoff AB (2006) Second generation of meniscus transplantation: in-vivo study with tissue engineered meniscus replacement. Arch Orthop Trauma Surg 126: 228-234.

Martínez H, Brackmann C, Enejder A, Gatenholm $P$ (2012) Mechanical stimulation of fibroblasts in micro-channeled bacterial cellulose scaffolds enhances production of oriented collagen fibers. J Biomed Mater Res A 100: 948-957.
McDevitt CA, Weber RJ (1990) The ultrastructure and biochemistry of meniscal cartilage. Clin Orthop 252: 8-18.

McDevitt CA, Miller RR, Spindler KP (1992) The cells and cell matrix interactions of the meniscus. In: Mow VC, Arnoczky SP, Jackson DW (eds) Knee Meniscus: Basic and Clinical Foundations. Raven Press, New York, pp29-36.

McGinity JB, Geuss LF, Marvin RA (1977) Partial or total meniscectomy: a comparative analysis. J Bone Joint Surg Am 59: 763-766.

Mi Z, Ghivizzani SC, Lechman E, Glorioso JC, Evans CH, Robbins PD (2003) Adverse effects of adenovirusmediated gene transfer of human transforming growth factor beta 1 into rabbit knees. Arthritis Res Ther 5: R132139.

Milachowski KA, Weismeier K, Wirth CJ (1989) Homologous meniscus transplantation. Experimental and clinical results. Int Orthop 13: 1-11.

Monllau JC, Gelber PE, Abat F, Pelfort X, Abad R, Hinarejos P, Tey M (2011) Outcome after partial medial meniscus substitution with the collagen meniscal implant at a minimum of 10 years' follow-up. Arthroscopy 27: 933-943.

Mow VC, Ratcliffe A, Chern KY, Kelly M (1992) Structure and function relationships on the menisci in the knee. In: Mow VC, Arnoczky SP, Jackson DW (eds) Knee Meniscus: Basic and Clinical Foundations. Raven Press New York, pp37-57.

Mueller SM, Schneider TO, Shortkroff S, Breinan HA, Spector M (1999) Alpha-smooth muscle actin and contractile behavior of bovine meniscus cells seeded in type I and type II collagen-GAG matrices. J Biomed Mater Res 45: 157-166.

Muraglia A, Cancedda R, Quarto R (2000) Clonal mesenchymal progenitors from human bone marrow differentiate in vitro according to a hierarchical model. J Cell Sci 113: 1161-1166.

Murphy JM, Fink DJ, Hunziker EB, Barry FP (2003) Stem cell therapy in a caprine model of osteoarthritis. Arthritis Rheum 48: 3464-3474.

Muschler GF, Nitto H, Boehm CA, Easley KA (2001) Age- and gender-related changes in the cellularity of human bone marrow and the prevalence of osteoblastic progenitors. J Orthop Res 19: 117-125.

Nakata K, Shino K, Hamada M, Mae T, Miyama T, Shinjo H, Horibe S, Tada K, Ochi T, Yoshikawa H (2001) Human meniscus cell: characterization of the primary culture and use for tissue engineering. Clin Orthop Relat Res 391 Suppl: S208-218.

Noble J, Turner PG (1986) The function, pathology, and surgery of the meniscus. Clin Orthop Relat Res 210: 62-68.

Northmore-Ball MD, Dandy DJ (1982) Long term results of arthroscopic partial meniscectomy. Clin Orthop 167: 34-42.

O'Connor BL (1984) The mechanoreceptor innervation of the posterior attachments of the lateral meniscus of the dog knee joint. J Anat 138: 15-26.

O'Connor BL, McConnaughey JS (1978) The structure and innervation of cat knee menisci and their relation to a "sensory hypothesis" of meniscal function. Am J Anat 153: 431-442. 
Pabbruwe MB, Kafienah W, Tarlton JF, Mistry S, Fox DJ, Hollander AP (2010) Repair of meniscal cartilage white zone tears using a stem cell/collagen-scaffold implant. Biomaterials 31: 2583-2591.

Pangborn CA, Athanasiou KA (2005) Effects of growth factors on meniscal fibrochondrocytes. Tissue Eng 11: 1141-1148.

Peretti GM, Randolph MA, Caruso EM, Rossetti F, Zaleske DJ (1998) Bonding of cartilage matrices with cultured chondrocytes: an experimental model. J Orthop Res 16: 89-95.

Peretti GM, Bonassar LJ, Caruso EM, Randolph MA, Trahan CA, Zaleske DJ (1999) Biomechanical analysis of a chondrocyte-based repair model of articular cartilage. Tissue Eng 5: 317-326.

Peretti GM, Caruso EM, Randolph MA, Zaleske DJ (2001) Meniscal repair using engineered tissue. J Orthop Res 19: 278-285.

Peretti GM, Gill TJ, Xu JW, Randolph MA, Morse KR, Zaleske DJ (2004) Cell-based therapy for meniscal repair: a large animal study. Am J Sports Med 32: 146-158.

Peretti GM, Scotti C, Pozzi A, Mangiavini L, Vitari F, Domeneghini C, Fraschini G (2008) Bonding of meniscal tissue: a nude mouse repair model. Sport Sci Health 3: 47-52.

Petri M, Ufer K, Toma I, Becher C, Liodakis E, Brand S, Haas P, Liu C, Richter B, Haasper C, von Lewinski G, Jagodzinski M (2012) Effects of perfusion and cyclic compression on in vitro tissue engineered meniscus implants. Knee Surg Sports Traumatol Arthrosc 20: 223 231.

Pittenger MF, Mackay AM, Beck SC, Jaiswal RK, Douglas R, Mosca JD, Moorman MA, Simonetti DW, Craig S, Marshak DR (1999) Multilineage potential of adult human mesenchymal stem cells. Science 284: 143-147.

Pujol N, Boisrenoult P (2009) Meniscus and Osteoarthritis. In: Beaufils P, Verdonk R (eds) The Meniscus. Springer-Verlag, Berlin Heidelberg, pp 61-66.

Renstrom P, Johnson RJ (1990) Anatomy and biomechanics of the menisci. Clin Sports Med 9: 523-538.

Rodkey WG, Steadman JR, Li ST (1999) A clinical study of collagen meniscus implants to restore the injured meniscus. Clin Orthop Relat Res 367 (Suppl): S281-S292.

Rodkey WG, DeHaven KE, Montgomery WH 3rd, Baker CL Jr, Beck CL Jr, Hormel SE, Steadman JR, Cole BJ, Briggs KK (2008) Comparison of the collagen meniscus implant with partial meniscectomy. A prospective randomized trial. J Bone Joint Surg Am 90: 1413-1426.

Rouwkema J, Gibbs S, Lutolf MP, Martin I, VunjakNovakovic G, Malda J (2011) In vitro platforms for tissue engineering: implications for basic research and clinical translation. J Tissue Eng Regen Med 5: e164-167.

Sakaguchi Y, Sekiya I, Yagishita K, Muneta T (2005) Comparison of human stem cells derived from various mesenchymal tissues: superiority of synovium as a cell source. Arthritis Rheum 52: 2521-2529.

Schmidt MB, Chen EH, Lynch SE (2006) A review of the effects of insulin-like growth factor and platelet derived growth factor on in vivo cartilage healing and repair. Osteoarthritis Cartilage 14: 403-412.
Scordino LE, Deberardino TM (2012) Biologic enhancement of meniscus repair. Clin Sports Med 31: 91100.

Scotti C, Pozzi A, Mangiavini L, Vitari F, Boschetti F, Domeneghini C, Fraschini G, Peretti GM (2009) Healing of meniscal tissue by cellular fibrin glue: an in vivo study. Knee Surg Sports Traumatol Arthrosc 17: 645-651.

Scotti C, Tonnarelli B, Papadimitropoulos A, Scherberich A, Schaeren S, Schauerte A, Lopez-Rios J, Zeller R, Barbero A, Martin I (2010) Recapitulation of endochondral bone formation using human adult mesenchymal stem cells as a paradigm for developmental engineering. Proc Natl Acad Sci USA 107: 7251-7256.

Scotti C, Osmokrovic A, Wolf F, Miot S, Peretti GM, Barbero A, Martin I (2012) Response of human engineered cartilage based on articular or nasal chondrocytes to interleukin-1 $\beta$ and low oxygen. Tissue Eng Part A 18: 362-372.

Seedhom BB, Hargreaves DJ (1979) Transmission of the load in the knee joint with special reference to the role of menisci: Part II. Experimental results, discussion and conclusions. Eng Med 8: 220-228.

Setton LA, Guilak F, Hsu EW, Vail TP (1999) Biomechanical factors in tissue engineered meniscal repair. Clini Orthop 367S: S245-S272.

Shaffer B, Kennedy S, Klimkiewicz J, Yao L (2000) Preoperative sizing of meniscal allografts in meniscus transplantation. Am J Sports Med 28: 524-533.

Shelbourne KD, Carr DR (2003) Meniscal repair compared with meniscectomy for bucket-handle medial meniscal tears in the anterior cruciate ligament-repaired knee. Am J Sports Med 31: 718-723.

Shrive NG, O'Connor, Goodfellow JW (1978) Loadbearing in the knee joint. Clin Orthop 131: 279-287.

Siegel MG, Roberts CS (1993) Meniscal allografts. Clin Sports Med 12: 59-80.

Sommerlath KG (1991) Results of meniscal repair and partial meniscectomy in stable knees. Int Orthop 15: 347 350 .

Stapleton TW, Ingram J, Katta J, Knight R, Korossis S, Fisher J, Ingham E (2008) Development and characterization of an acellular porcine medial meniscus for use in tissue engineering. Tissue Eng Part A 14: 505-518.

Steadman JR, Rodkey WG (2005) Tissue-engineered collagen meniscus implants: 5- to 6-year feasibility study results. Arthroscopy 21: 515-525.

Steenbrugge F, Verdonk R, Hürel C, Verstraete K (2004) Arthroscopic meniscus repair: inside-out technique vs. Biofix meniscus arrow. Knee Surg Sports Traumatol Arthrosc 12: 43-49.

Steinert AF, Palmer GD, Capito R, Hofstaetter JG, Pilapil C, Ghivizzani SC, Spector M, Evans CH (2007) Genetically enhanced engineering of meniscus tissue using ex vivo delivery of transforming growth factor-beta 1 complementary deoxyribonucleic acid. Tissue Eng 13: 2227-2237.

Stone KR, Rodkey WG, Webber R, McKinney L, Steadman JR (1992) Meniscal regeneration with copolymeric collagen scaffolds. In vitro and in vivo studies evaluated clinically, histologically, and biochemically. Am J Sports Med 20: 104-111. 
Stone KR, Steadman JR, Rodkey WG, Li ST (1997) Regeneration of meniscal cartilage with use of a collagen scaffold. Analysis of preliminary data. J Bone Joint Surg Am 79: 1770-1777.

Tan Y, Zhang Y, Pei M. (2010) Meniscus reconstruction through coculturing meniscus cells with synovium-derived stem cells on small intestine submucosa - a pilot study to engineer meniscus tissue constructs. Tissue Eng Part A 16: 67-79.

Tay AG, Farhadi J, Suetterlin R, Pierer G, Heberer M, Martin I (2004) Cell yield, proliferation, and postexpansion differentiation capacity of human ear, nasal, and rib chondrocytes. Tissue Eng 10: 762-770.

Toyonaga T, Uezaki N, Chikama H (1983) Substitute meniscus of Teflon-net for the knee joint of dogs. Clin Orthop Relat Res 179: 291-297.

Vacanti CA, Langer R, Schloo B, Vacanti JP (1991) Synthetic polymers seeded with chondrocytes provide a template for new cartilage formation. Plast Reconstr Surg 88: $753-759$.

van Tienen TG, Heijkants RG, Buma P, de Groot JH, Pennings AJ, Veth RP (2002) Tissue ingrowth and degradation of two biodegradable porous polymers with different porosities and pore sizes. Biomaterials 23: 17311738 .

van Tienen TG, Hannink G, Buma P (2009) Meniscus replacement using synthetic materials. Clin Sports Med 28: $143-156$

Verdonk P, Vererfve P (2009) Traumatic lesions: stable knee, ACL knee. In: Beaufils P, Verdonk R (eds) The Meniscus. Springer-Verlag, Berlin Heidelberg, pp 45-50.

Verdonk PC, Demurie A, Almqvist KF, Veys EM, Verbruggen G, Verdonk R. Transplantation of viable meniscal allograft. Survivorship analysis and clinical outcome of one hundred cases (2005) J Bone Joint Surg Am 87: 715-724.

Verdonk R, Almqvist KF, Huysse W, Verdonk PC (2007) Meniscal allografts: indications and outcomes. Sports Med Arthrosc 15: 121-125.

Verdonk R, Verdonk P, Heinrichs EL (2009) Polyurethane meniscus implant: technique. In: Beaufils P, Verdonk R (eds) The Meniscus. Springer-Verlag, Berlin Heidelberg, pp 389-394.

Verdonk R, Verdonk P, Huysse W, Forsyth R, Heinrichs EL (2011) Tissue ingrowth after implantation of a novel, biodegradable polyurethane scaffold for treatment of partial meniscal lesions. Am J Sports Med 39: 774-782.

Voloshin AS, Wosk J (1983) Shock absorption of meniscectomized and painful knees: a comparative in vivo study. J Biomed Eng 5: 157-161.

Walker PS, Erkman MJ (1975) The role of the meniscus in force transmission across the knee. Clin Orthop 109: 184-192.

Walsh CJ, Goodman D, Caplan AI, Goldberg VM (1999) Meniscus regeneration in a rabbit partial meniscectomy model. Tissue Eng 5: 327-337.
Weinand C, Peretti GM, Adams SB Jr, Bonassar LJ, Randolph MA, Gill TJ (2006a) An allogenic cell-based implant for meniscal lesions. Am J Sports Med 34: 17791789.

Weinand C, Peretti GM, Adams SB Jr, Randolph MA, Savvidis E, Gill TJ (2006b) Healing potential of transplanted allogeneic chondrocytes of three different sources in lesions of the avascular zone of the meniscus: a pilot study. Arch Orthop Trauma Surg 126: 599-605.

Welsing RT, van Tienen TG, Ramrattan N, Heijkants R, Schouten AJ, Veth RP, Buma P (2008) Effect on tissue differentiation and articular cartilage degradation of a polymer meniscus implant: A 2-year follow-up study in dogs. Am J Sports Med 36: 1978-1989.

Wendt D, Riboldi SA, Cioffi M, Martin I (2009) Potential and bottlenecks of bioreactors in $3 \mathrm{D}$ cell culture and tissue manufacturing. Adv Mater 21: 3352-3367.

Wilson AS, Legg PG, McNeur JC (1969) Studies on the innervation of the medial meniscus in the human knee joint. Anat Rec 165: 485-491.

Wirth CJ, Peters G, Milachowski KA, Weismeier KG, Kohn D (2002) Long-term results of meniscal allograft transplantation. Am J Sports Med 30: 174-181.

Wojtys EM, Chan DB (2005) Meniscus structure and function. Instr Course Lect 54: 323-330.

Wood DJ, Minns RJ, Strover A (1990) Replacement of the rabbit medial meniscus with a polyester-carbon fibre bioprosthesis. Biomaterials 11: 13-16.

Yoo JJ, Bichara DA, Zhao X, Randolph MA, Gill TJ (2011) Implant-assisted meniscal repair in vivo using a chondrocyte-seeded flexible PLGA scaffold. J Biomed Mater Res A 99: 102-108.

Zaffagnini S, Giordano G, Vascellari A, Bruni D, Neri MP, Iacono F, Kon E, Presti ML, Marcacci M (2007) Arthroscopic collagen meniscus implant results at 6 to 8 years follow up. Knee Surg Sports Traumatol Arthrosc 15: 175-183.

Zaffagnini S, Marcheggiani Muccioli GM, Lopomo N, Bruni D, Giordano G, Ravazzolo G, Molinari M, Marcacci M (2011) Prospective long-term outcomes of the medial collagen meniscus implant versus partial medial meniscectomy: a minimum 10-year follow-up study. Am J Sports Med 39: 977-985.

Zaleskas JM, Kinner B, Freyman TM, Yannas IV, Gibson LJ, Spector M (2001) Growth factor regulation of smooth muscle actin expression and contraction of human articular chondrocytes and meniscal cells in a collagenGAG matrix. Exp Cell Res 270: 21-31.

Zellner J, Mueller M, Berner A, Dienstknecht T, Kujat R, Nerlich M, Hennemann B, Koller M, Prantl L, Angele M, Angele P (2010) Role of mesenchymal stem cells in tissue engineering of meniscus. J Biomed Mater Res A 94: 1150-1161.

Zuk PA, Zhu M, Ashjian P, De Ugarte DA, Huang JI, Mizuno H, Alfonso ZC, Fraser JK, Benhaim P, Hedrick $\mathrm{MH}$ (2002) Human adipose tissue is a source of multipotent stem cells. Mol Biol Cell 13: 4279-4295. 